\title{
WestVirginiaUniversity
}

THE RESEARCH REPOSITORY @ WVU

Graduate Theses, Dissertations, and Problem Reports

2017

\section{Three Essays on State and Federal Regulations}

\author{
Shree Baba Pokharel
}

Follow this and additional works at: https://researchrepository.wvu.edu/etd

\section{Recommended Citation}

Pokharel, Shree Baba, "Three Essays on State and Federal Regulations" (2017). Graduate Theses, Dissertations, and Problem Reports. 6429.

https://researchrepository.wvu.edu/etd/6429

This Dissertation is protected by copyright and/or related rights. It has been brought to you by the The Research Repository @ WVU with permission from the rights-holder(s). You are free to use this Dissertation in any way that is permitted by the copyright and related rights legislation that applies to your use. For other uses you must obtain permission from the rights-holder(s) directly, unless additional rights are indicated by a Creative Commons license in the record and/ or on the work itself. This Dissertation has been accepted for inclusion in WVU Graduate Theses, Dissertations, and Problem Reports collection by an authorized administrator of The Research Repository @ WVU.

For more information, please contact researchrepository@mail.wvu.edu. 


\title{
Three Essays on State and Federal Regulations
}

\author{
Shree Baba Pokharel \\ Dissertation submitted \\ to the College of Business and Economics \\ at West Virginia University \\ in partial fulfillment of the requirements \\ for the degree of \\ Doctor of Philosophy in \\ Economics \\ Joshua C. Hall, Ph.D., Chair \\ Donald J. Lacombe, Ph.D. \\ John Deskins, Ph.D. \\ Bryan C. McCannon, Ph.D. \\ Department of Economics \\ Morgantown, West Virginia \\ 2017
}

Keywords: Wine Campaign Contributions, Wine Excise Taxes, SDM and Hierarchical SLX Models, Wine Value Chain, State and Federal Regulations Copyright 2017 Shree Baba Pokharel 


\section{Abstract}

Three Essays on State and Federal Regulations

Shree Baba Pokharel

This dissertation consists of three essays on state and federal regulations in the US. Each paragraph below refers to the three abstracts for the three chapters in this dissertation, respectively.

Given the growing importance of the wine industry in the US, wine special interests are on the rise. Data shows that campaign contributions from the wine industry to officials running for state offices have increased over time. Given this reality, one can expect wine excise tax to remain low in states that receive higher campaign contributions. In addition, there are theoretical and empirical reasons to believe that these tax rates are interdependent based on Tiebout competition and yardstick competition. Based on this reasoning, one can hypothesize wine excise tax rates to be spatially dependent. In this study, I test this hypothesis using state-level campaign contributions data from the National Institute on Money in State Politics and Distilled Spirits Council of the US, Inc. and find that there is strong statistical evidence of spatial dependence between state wine excise tax rates.

Previous studies showed that high stakes state exit exams have both positive and negative influence on educational outcomes. Its effect on high school graduation rates in particular was negative. However, these studies do not take into account the embedded nature of school districts within state education systems to explain these variations. Additionally, they also ignore possible spatial spillovers across school districts. In this paper, we account for both- the hierarchical nature of the data and the possible spatial spillovers, to provide estimates. Using school-district- and statelevel data for high school graduation rates for 46 states and 8,636 school districts in the US for the year 2013 from The Hechinger Report and the National Center for Education Statistics, using Bayesian Hierarchical SLX model, we find that state exit exams have no statistically significant influence on graduation rates.

Significant number of previous studies looked at the macro level impacts or the more specific narrow impacts of federal regulatory restrictions on economic outcomes. Using Regdata, a numerical quantification of federal regulatory restrictions across all North American Industry Classification System industries, this paper quantifies the number of federal restrictions on the wine value chain. The wine value chain comprises of "Wineries" (NAICS: 31213), "Wine and Distilled Alcoholic Beverage Merchant Wholesalers" (NAICS: 42482), and "Beer, Wine and Liquor Sales" (NAICS: 44531). This paper finds that the wine value chain faced an overwhelming estimated 100,000 federal regulatory restrictions in 2012. This paper also find that these restrictions are persistent. 


\section{Dedication}

This dissertation is dedicated to my family in Nepal, especially my parents. Thank you for letting me go to a foreign country at a young age and chase my dreams. 


\section{Acknowledgements}

I would like to thank my advisor, Dr. Joshua C. Hall, for the push and continual support throughout these years. Getting to this point would have been very difficult without your input. I would also like to thank my committee members, Dr. Donald J. Lacombe, Dr. John Deskins, and Dr. Byran McCannon for their invaluable feedback. Incoming Class of 2012, I thank each one of you for being there in good times and in bad. Especially, Sriparna Ghosh, thank you for being there always. Elham Erfanian, thank you for your time and help with spatial econometrics. Shivani R. Khan, my forever listening ear, thank you. I would also like to thank Ms. Debbie Harrell at Salem College, NC, and Dr. Herb Schuette for being the best undergraduate mentors one can think of. I thank you for preparing me for my doctoral work. Finally, my dear husband, thank you for being my rock. 


\section{Table of Contents}

List of Figures

List of Tables vii

1 Wine Industry Campaign Contributions and Wine Excise Taxes: Evidence from US States 1

1.1 Introduction . . . . . . . . . . . . . . . . . . 1

1.2 Data and Empirical Approach . . . . . . . . . . . . . . 6

1.3 Empirical Results and Robustness Checks . . . . . . . . . . . . 14

1.4 Conclusion . . . . . . . . . . . . . . . . . . . . 17

2 State Exit Exams and Graduation Rates: A Hierarchical SLX Modelling Approach 22

2.1 Introduction . . . . . . . . . . . . . . . . . . . . . . 22

2.2 Statistical Methodology _. . . . . . . . . . . . . . . 26

2.2 .1 Hierarchical Models . . . . . . . . . . . . . . . . . . . . . 26

2.2 .2 The Hierarchical SLX Model . . . . . . . . . . . . . . . . . 29

2.3 Data . . . . . . . . . . . . . . . . . . . . . . . 32

2.3 .1 Level 1 Data. . . . . . . . . . . . . . . . . . . . . . . . . 32

2.3.2 Level 2 Data. . . . . . . . . . . . . . . . . . . . . . 34

2.4 Empirical Results . . . . . . . . . . . . . . . . . . . . . . . . 34

2.4 .1 Level 1 Results . . . . . . . . . . . . . . . . . . . . . . 35

2.4 .2 Level 2 Results . . . . . . . . . . . . . . . . . . . . . 38

2.5 Conclusion . . . . . . . . . . . . . . . . . . . . . . . . 39

3 Federal Regulations in the United States Wine Value Chain Over Time 44

3.1 Introduction . . . . . . . . . . . . . . . . . . . . . 44

3.2 Data . . . . . . . . . . . . . . . . . . . . 47

3.3 Empirical Results . . . . . . . . . . . . . . . . . . . . . . 51

3.4 Limitations . . . . . . . . . . . . . . . . . . . . . . . 54

3.5 Conclusion . . . . . . . . . . . . . . . . . 56 


\section{List of Figures}

1.1 Wine Consumption in the US from 1991-2015 . . . . . . . . . . .

1.2 State Wine Excise Taxes and Wine Contributions from the Wine Industry to Officials Running for State Offices for a 18-year Time Period 4

1.3 Wine Excise Taxes in 48 Contiguous US States in 2012 . . . . . . . . 5

2.1 States with and without State Exit Exams . . . . . . . . . . . 23

3.1 Total Direct Federal Restrictions on Each Wine Value Chain Over Time (1997-2012) . . . . . . . . . . . . . . . . . . 61

3.2 Total Input Federal Restrictions on Each Wine Value Chain Over Time

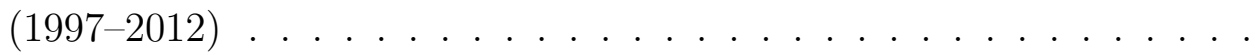

3.3 Total (Direct + Indirect) Federal Restrictions on Each Wine Value

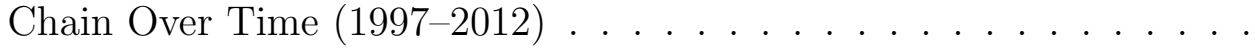




\section{List of Tables}

1.1 Summary Statistics . . . . . . . . . . . . . . . . . .

1.2 Lagrange Multiplier (LM) and Likelihood Ratio (LR) Tests for the Presence of Spatial-and Time-Fixed Effects . . . . . . . . . . . . . . 11

1.3 Lagrange Multiplier (LM) and Likelihood Ratio(LR) Tests for the Presence of Spatial-and Time-Fixed Effects . . . . . . . . . . . . . .

1.4 The Effect of Wine-Industry Campaign Contributions on Wine Excise Taxes for 48 Contiguous US States Using 4-Nearest-Neighbor Matrix

1.5 The Effect of Wine-Industry Campaign Contributions on Wine Excise Taxes for 44 Contiguous US States Using 4-Nearest-Neighbor Matrix

1.6 The Effect of Wine-Industry Campaign Contributions on Wine Excise Taxes for 48 Contiguous US States Using 5-Nearest-Neighbor Matrix

2.1 Summary Statistics . . . . . . . . . . . . . . . .

2.2 Level 1 Results with State Exit Exams as Level 2 Variable with 10 Nearest-Neighbor W Matrix . . . . . . . . . . . . . . . . . . . . . . 42

2.3 State Exit Exam (Level 2) Results with 2 nearest-neighbor W matrix 43

3.1 Direct, Indirect, and Total Federal Regulation Imposed on Wineries . 57

3.2 Direct, Indirect, and Total Federal Regulation Imposed on Wholesale Distribution . . . . . . . . . . . . . . . 58

3.3 Direct, Indirect, and Total Federal Regulation Imposed on Wine Retail Sales . . . . . . . . . . . . . . . . . . . 59

3.4 Comprehensive Measure of Federal Restrictions on each Value Chain 60 


\section{Chapter 1}

\section{Wine Industry Campaign Contributions and Wine Excise Taxes: Evidence from US States}

\section{$1.1 \quad$ Introduction}

State and local government expenditures have been increasing over time in the United States. With this growth in expenditures, there has been an increasing need for tax revenue generation by state governments. States revenues come primarily from sales, property, and income taxes. The increasing need for further revenue generation and voter opposition to the prospect of further increasing broad-based taxes has led state and local governments to search for other sources of revenue collection.

As a popular choice, state and local governments have started to selectively tax goods that pose negative externalities or are considered "sinful". For such goods, they levy "sin taxes". Sin taxes are one form of an excise tax. The intention of this tax is to increase revenue and, by increasing the after-tax price of the good, reduce negative externalities that these goods impose. Hence, excise taxes could be assumed to be set high if the primary goal is revenue generation and negative externality reduction. Such goods include tobacco, alcohol, and motor fuels, historically, and more recently, 
goods such as foods that are high in sugar and transfats, to name a few (Hoffer et al., 2014).

However, when one such good is studied in detail- alcohol, and more specifically, wine, there has only been a 5-cent increase in excise taxes in a 18-year time period. This poses a question as to why there is such a small increase in excise tax if the main goal is to increase revenue and to decrease negative externality. The reason might be because of wine special interest groups furthering their own interests by keeping the excise tax of wine low.

I chose the alcohol industry, and specifically the wine industry for two reasons. First, even though the United States taxed wine as early as 1631 (Sumner, 1892; Hines, 2007), it a fairly new industry in terms of mass production. Second, it is growing in terms of exports, imports, and consumption, and has the potential to increase revenue in future, making it an important industry to study.

The United States was the $7^{\text {th }}$ largest exporter and the $4^{\text {th }}$ largest producer of wine in 2012. In 2009, the US accounted for approximately $10 \%$ of the worlds wine production (Thornton, 2013). Approximately 14\% of the world's export volume came from US produced wine (Anderson and Nelgen, 2011). A report published by MKF Research LLC claims that wineries are now present in all 50 states with $\$ 11.4$ billion in winery sales revenue. ${ }^{1}$ In North Carolina alone, there are 44 new wineries and 1,000 acres of vineyards, corresponding with a as tobacco acreage declined overtime (MKF Research, LLC, 2007). Figure 1.1 shows an almost doubling of total table wine consumption in the US from 1991-2015, which increased from a little less than 400 million gallons in 1991 to about 800 million gallons in 2015 (Wine Institute, 2016). It represents a huge portion of total wine consumption each year, where total wine consumption increased from 450 million gallons in 1991 to approximately 900 million gallons in 2015 (Wine Institute, 2016).

Figure 1.2 shows average state wine excise tax in years 1996 and 2012. This is

\footnotetext{
${ }^{1}$ This report has been published with support from Wine America, the Wine Institute, Winegrape Growers of America and the National Grape and Wine Initiative.
} 
Figure 1.1: Wine Consumption in the US from 1991-2015

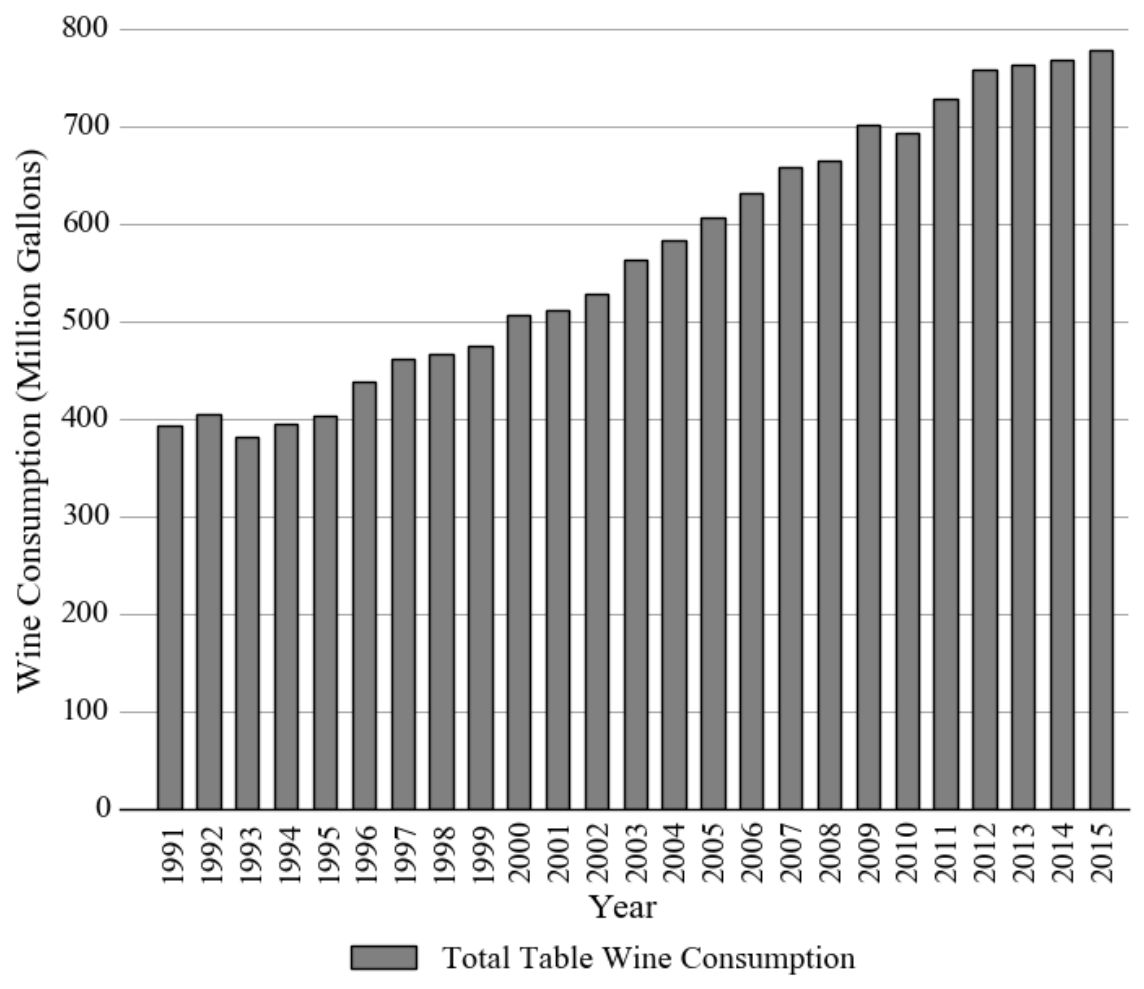

indicated by the color black in the figure. Average wine contributions from the wine industry to officials running for state offices for the same years is shown in grey. While the average state excise tax increase was only approximately 5 -cents or $7.5 \%$ over the course of 18 - years, the average dollar amount of campaign contributions has increased by well over $700 \%$ in the same 18- year time period. In this context, Becker (1983) wrote:

Political influence is not simply fixed by the political process, but can be expanded by expenditures of time and money on campaign contributions, political advertising, and in other ways that exert political pressure.

In terms of special interest group influences, previous studies have looked at the tobacco industry. Holcombe (1997) and Hoffer (2016) found tobacco special interest to negatively influence tobacco excise taxes, while Besley and Rosen (1998), Devereux et al. (2007), and Fredriksson and Mamun (2008), found little to no impact of tobacco special interest on tobacco excise tax rates. Studies have also looked at alcohol taxes 
Shree B. Pokharel Chapter 1. Campaign Contributions and Wine Excise Taxes 4

Figure 1.2: State Wine Excise Taxes and Wine Contributions from the Wine Industry to Officials Running for State Offices for a 18-year Time Period

$\$ 1.00$

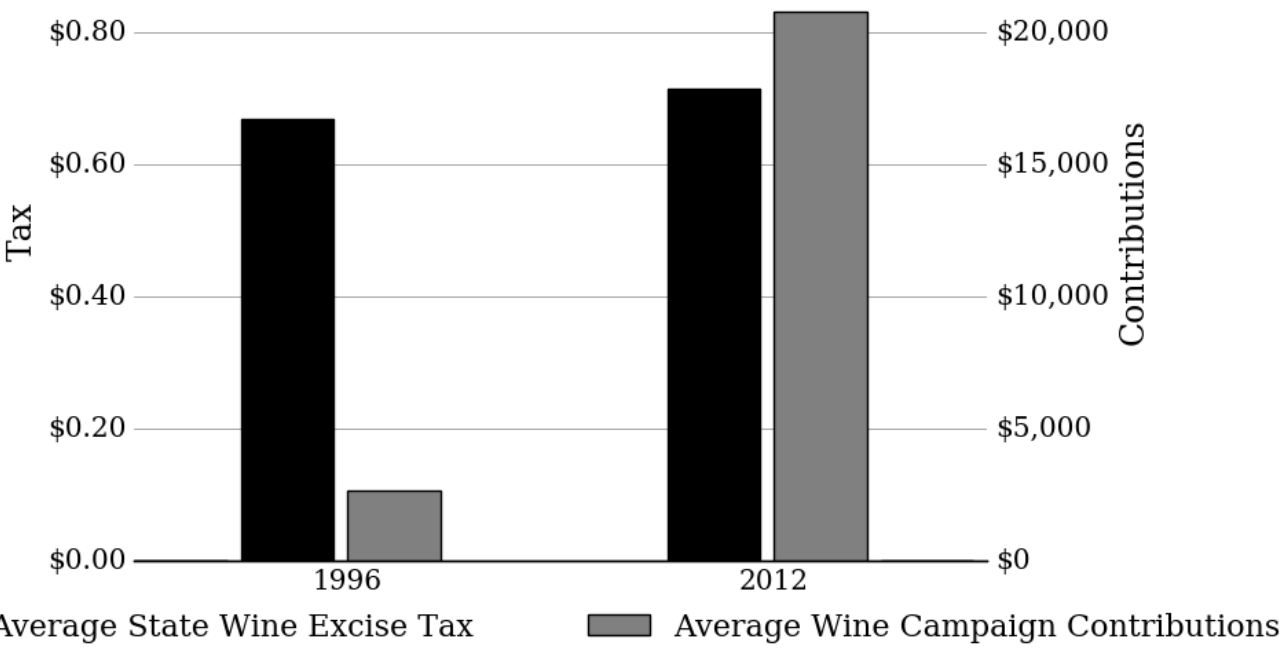

(taxes on beer, wine, and spirits) on economic outcomes such as pricing (MacDonald, 1986; Nelson, 1990; Sass and Saurman, 1996), consumption behaviors and health outcomes (Fell et al., 2009; Miron and Tetelbaum, 2009; Elder et al., 2010). Except for Hoffer (2016), these studies do not take into account the spatial dependency in tax rates between states.

In studies of tax rates, there are theoretical and empirical reasons to believe that these rates are spatially correlated. Theoretically, inferences can be made based on Tiebout (Tiebout, 1956) and yardstick competition (Brueckner and Saavedra, 2001). Empirically, recent literature have shown that tax rates are interdependent (Deskins and Hill, 2010) primarily because of mobility of tax bases (Brueckner, 2003). For example, wine sellers compete with each other for consumers. Since consumers vote with their feet, consumers straddling state borders for cheaper wine is not uncommon. States establishing wine taxes as a function of neighbor's tax rates is, then, not a surprising outcome. With respect to this study, the data follow spatial pattern as well. For instance, Missouri increased its wine excise tax from 36 cents in 2000 to 42 cents in 2004. Arkansas increased its tax from 75 cents in 2008 to 77 cents in 2010. 
At the same time, Mississippi also increased its tax rate from 35 cents to 43 cents. Tennessee increased its tax rate from $\$ 1.215$ in 2010 to $\$ 1.27$ in 2012 .

Leaving spatial dependency out of the equation would ignore a possible explanation as to why there is a difference among wine excise taxes between states. While growing need for government expenditure leads to the need for additional revenue generation (Hoffer, 2016), tax competition points towards higher taxes in neighboring states (Deskins and Hill, 2010). Following this logic, one should see higher taxes everywhere. However, this is not seen in practice. There is a huge variance among wine excise taxes within US states, with the highest in Florida with $\$ 2.25$ per gallon in 2012 to the lowest of 0 cents per gallon in New Hampshire, Pennsylvania, Utah, and Wyoming. Figure 1.3 depicts the differences in wine excise tax rates among 48 contiguous US states in 2012.

Figure 1.3: Wine Excise Taxes in 48 Contiguous US States in 2012

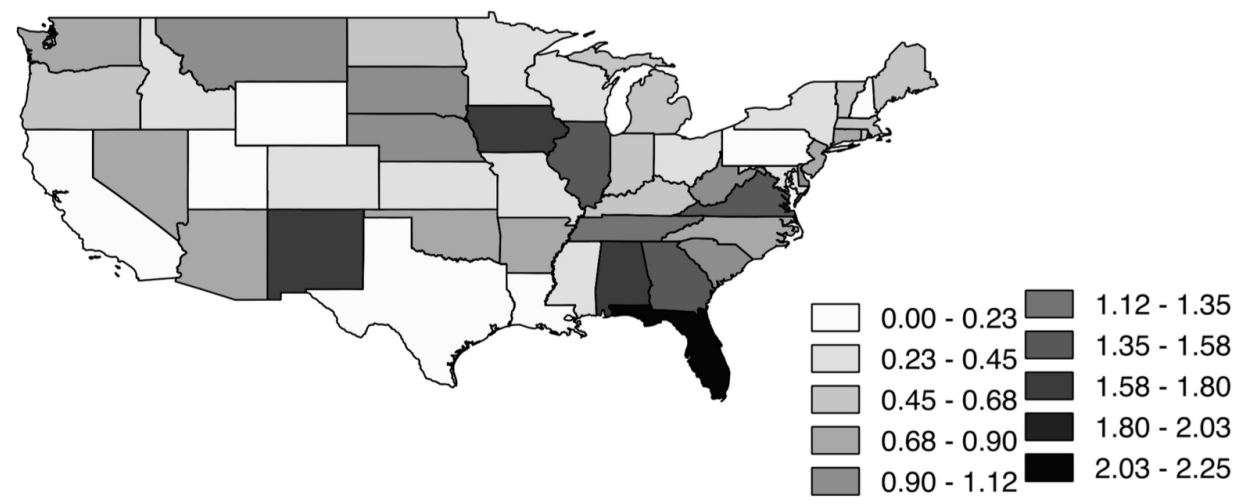

In this study, I hypothesize that state wine excise taxes are spatially dependent. I employ the Spatial Durbin Model to test my hypothesis and find strong statistical evidence that there is spatial dependency in wine excise tax rates between states. I find that higher campaign contributions from the wine industry in a state leads to a lower wine excise tax for both the given state and its neighbors.

There are two contributions of this paper. First, it is the first study to account for the effect of campaign contributions in the alcohol industry, specifically, the wine industry. Previously, studies used total production as a proxy for special interests 
groups in the tobacco industry (Holcombe, 1997; Hoffer, 2016). Second, it is also the first study that looks at the wine industry using a spatial econometric framework. Since I account for spatial dependence, I capture the "spillover" effects or neighborhood effects of changes in the explanatory variables, which would have not been captured had spatial dependence not been accounted for.

The remainder of the paper proceeds as follows. Section 2 describes the data and empirical approach used in this study. Section 3 describes the results and Section 4 concludes.

\subsection{Data and Empirical Approach}

In this study, I follow Hoffer (2016), who looks at the tobacco excise taxes. Instead, I employ state wine excise tax as the dependent variable. The dependent variable is state wine excise tax rate per gallon for 48 contiguous US states from 1996-2012. ${ }^{2}$ Data on wine excise taxes is obtained from the Distilled Spirits Council of the United States, Inc., the World Tax Database, and Tax Foundation. According to Tax Foundation, wine excise tax "rates are those applicable to off-premise sales of 11\% ABV non-carbonated $750 \mathrm{~mL}$ containers" (Jordan, S and Drenkard, S, 2015). In other words, wine excise tax rate is applicable to retail store sales and not to wine sales in restaurants. For example, Florida has a wine tax rate of $\$ 2.25$. This means that for every gallon of wine bought at an "off-premise" site in Florida, a consumer pays $\$ 2.25$ in excise taxes.

There are three categories of explanatory variables used in this study that are likely to affect wine excise tax rates: Primary Variables, State Controls, and Demographic Controls. Wine and Beer fall under the Primary Variables category and represent the major variables of interest. Wine proxies for wine-industry special interest in a state while Beer proxies for beer-industry special interest in a state. Wine is the author's calculation and is defined as the dollar amount of wine-industry campaign

\footnotetext{
${ }^{2}$ I exclude Alaska and Hawaii for spatial econometrics issues discussed later.
} 
contribution to officials running for state offices per 100 state residents. For example, campaign contribution from the wine industry to officials running for state offices in California in 2012 was $\$ 1.04$ per 100 residents. This amounts to approximately $\$ 400$ thousand in campaign contributions just for the state of California in a year.

Since wine and beer can be thought of as substitutes, Beer is used to control for any substitution effects and represents dollar amount of beer-industry campaign contribution to officials running for state offices per 100 residents. ${ }^{3}$ Beer variable is also the authors' calculation. Both Wine and Beer are obtained from the National Institute on Money in State Politics and are inflation-adjusted to 2010 dollars. Contributions from both individuals and non-individuals (business owners, persons or companies, for instance) are included in the contributions data by the National Institute on Money in State Politics.

In addition to the primary variables of interest, there are other state-government specific variables that fall under the State Controls category that are likely to affect wine excise taxes. There are four variables under this category-Gov_Term, Citizen, Growth_Rate, and Health. Gov_Term, Citizen, and Health are drawn primarily from special interest group literature, specifically, the tobacco special interest literature. I draw from the tobacco special interest literature as, to my knowledge, there are no studies on wine special interests.

Gov_Term represents a dummy variable with a value of 1 if the incumbent governor cannot again run for office due to a term limit and 0 otherwise. Hoffer (2016) finds a positive relationship between governor term limit and cigarette tax rates. Data for this variable is obtained from The Council of State Governments. Citizen measures citizen ideology. Its score ranges from 1 to 100, where 1 represents "most conservative" and 100 represents "most liberal". It can be hypothesized that states with more "liberal" citizens would be accepting of higher taxes due to the belief of a

\footnotetext{
${ }^{3}$ Wine and Beer can be hypothesized to be positively correlated. If such relationship does exist, including both variables would provide with incorrect estimates. I find that the collinearity coefficient between the two variables is 0.38, indicating that including both Beer and Wine in the analysis is justifiable.
} 
more involved role of government. Hoffer and Pellillo (2012) find a positive relationship between citizen idealogy and tobacco control funding. Citizen is obtained from Berry et al. (2010). Growth_Rate represents the 2-year growth rate in state spending. States under fiscal stress could be hypothesized to have a high demand for revenue, thus having a positive relationship with excise taxes. Data for Growth_Rate comes from The Council of State Governments. Health represents the dollar amount per capita spent by states on health expenditures. It is found to negatively affect cigeratte excise taxes (Hoffer, 2016). ${ }^{4}$ Health is obtained from the US Census Bureau.

Additionally, demographic controls are included in order to control for the demographic characteristics of a state's population. Under the Demographic Controls category, there are two variables- Pop65 and Popwhite that might affect state wine excise taxes in terms of population tastes for wine. Pop65 represents the percentage of state population over the age of 65 and Popwhite represents the percentage of Caucasian population in a state. Both Besley and Rosen (1998) and Devereux et al. (2007) find aged population to negatively affect cigarette tax rates. Data for these two variables is obtained from the US Census Bureau as well. The data used in this study is biannual due to the biannual nature of giving to political candidates, and ranges from 1996 to 2012. Table 1.1 presents summary statistics.

Table 1.1: Summary Statistics

\begin{tabular}{lrrrr}
\hline \multicolumn{1}{c}{ Variable } & Mean & St. Dev. & Min & \multicolumn{1}{c}{ Max } \\
\hline Wine Excise Tax per gallon (\$) & 0.69 & 0.51 & 0 & 2.25 \\
Wine Contribution per 100-residents (\$) & 0.33 & 0.79 & 0 & 7.43 \\
Beer Contribution per 100-residents (\$) & 0.70 & 1.07 & 0 & 9.84 \\
Governor Term Limit & 0.31 & 0.46 & 0 & 1 \\
Citizen & 49.45 & 15.73 & 8.45 & 95.97 \\
2-year State Spending Growth Rate (\$) & 11.56 & 6.88 & -5.74 & 40.26 \\
Health (\$) & 156.33 & 80.24 & 36.46 & 528.00 \\
Population over 65 & 12.80 & 1.57 & 8.42 & 18.56 \\
Percentage White & 84.17 & 9.40 & 60.73 & 98.70 \\
\hline
\end{tabular}

Note: N=432, Time Period: 1996-2012

\footnotetext{
${ }^{4}$ In this study, Hoffer (2016) looks at healthcare instead of just health. healthcare consists of state spending on health and hospitals.
} 
The mean wine excise tax rate is $\$ .69$. There is a lot of variation among states in terms of wine excise taxes. While states like New Hampshire, Pennsylvania, Utah, and Wyoming do not have wine excise taxes, ${ }^{5}$ Florida has the highest excise tax of $\$ 2.25$. There is a huge variation between states in terms of wine contribution per 100 state residents. While Oregon has a wine contribution per 100 residents of $\$ 7.43$, there are multiple states that do not have wine contributions. Beer contribution per 100 residents also varies significantly between states. While Beer in Mississippi is $\$ 9.84$, there are a large number of states without any beer campaign contributions. There is notable variation among citizen ideologies between states. Kentucky is the "most conservative" state with the score of 8.45 while Vermont is the "most liberal" state with a score of 95.97. The Growth_Rate variable also varies significantly from $-5.74 \%$ in Louisiana to $40.26 \%$ in Vermont and so does Health. Louisiana spends approximately $\$ 36$ per person on its health expenditures while Wyoming spends a staggering $\$ 528$. Utah has the least percentage of population over the age of 65 while Florida has the most. Mississippi has the least percentage of Caucasian population in the US while Maine has the most.

Since I hypothesize that the dependent variable and the independent variables have spatial component to them, I employ the Spatial Durbin Model (SDM) for this study. For readers not familiar with spatial models, I will first explain a family of related spatial models and then the model choice, SDM. The family of related spatial models can be represented as follows:

$$
\begin{aligned}
y_{i t} & =\rho \sum_{j=1}^{N} w_{i j} y_{j t}+x_{i t} \beta+\theta \sum_{j=1}^{N} w_{i j} x_{i t}+\mu_{i}+\lambda_{t}+u_{i} \\
u_{i} & =\delta \sum_{j=1}^{N} w_{i j} u_{i t}+\varepsilon_{i t}
\end{aligned}
$$

where $i$ represents cross-sectional units. For the purposes of this paper, $i$ represents US states and ranges from $i=1$ to $N$. $t$ represents the time dimension, i.e. year, and

\footnotetext{
${ }^{5}$ These four states are what are called "control" states. In control states, all wine sales are controlled by the state government and thus there are no explicit state excise taxes on wine. Therefore, they do not have wine excise taxes in a comparable sense.
} 
ranges from $t=1$ to $T$. Therefore, $y_{i t}$ represents an observation for the dependent variable in state $i$ in year $t$.

$x_{i t}$, the explanatory variable, is a row vector of observations with dimension $(1 \times$ $K) . \beta$ in Equation 1.1 is a $(K \times 1)$ vector of parameters associated with $x_{i t}$ variables, and is fixed and unknown. The terms $\mu_{i}$ and $\lambda_{t}$ represent space fixed effects and time fixed effects, respectively.

The spatially-lagged dependent variable and spatially-lagged explanatory variables are represented by $\rho$ and $\theta$, while the spatially-lagged error term is represented by $\delta$. The addition of these terms in association with $w_{i j}$ make the above model a spatial econometric model. In the model, $w_{i j}$ is an element of a spatial weight matrix, W. W symbolizes "neighbor-to-neighbor" relationships and has a $(N \times N)$ dimension. For example, if $i$ and $j$ are defined as neighbors, the $w_{i j}$ element is assigned a value of ' 1 ,' and ' 0 ' otherwise. In creating weight matrices, $\mathrm{W}$ is designed to be row-stochastic, meaning that rows of $\mathrm{W}$ sum to one. Hence, the term, $W y$ represents the weighted average of the surrounding $y$ 's. Similarly, $W x$ represents the weighted average of the surrounding explanatory variables, and $W u$ represents the surrounding error terms.

Since Equation 1.1 characterizes a family of spatial models, restricting parameters in the equation generates various spatial econometric models. By restricting $\theta$ and $\delta$ to 0 , I get spatial dependence only in the dependent variable. This type of model is called a Spatial Autoregressive Model (SAR). By setting $\rho=0$ and $\delta=0$, I see spatial dependence only in the independent variable. Such model is named the Spatial Lag of X (SLX) model. Similarly, setting $\rho=0$ and $\theta=0$, I see spatial dependence only in the error term; this model is named Spatial Error Model (SEM). Spatial Durbin Model (SDM) is obtained by setting $\delta$ to 0 . Spatial Durbin Error Model (SDEM) is represented by Equation 1.1. Space fixed effects $\left(\mu_{i}\right)$ and time fixed effects $\left(\lambda_{t}\right)$ in Equation 1.1 may be included in all models described above.

Table 1.2 reports Elhorst test findings for determining the presence of spaceand time-fixed effects (Elhorst, 2009). The Lagrange Multiplier(LM) tests check 
whether there is spatial correlation in the data. The null hypothesis, $H_{o}$ : No spatial dependence in the dependent variable, is tested by the LM Lag test, whereas, the null hypothesis, $H_{o}$ : No spatial dependence in the error term, is tested by the LM Error test for each specification. Standard Likelihood Ratio(LR) tests are performed to determine the joint significance of space-and time-fixed effects (Elhorst, 2014). The null hypotheses for such tests is that the presence of state fixed effects and year fixed effects are represented by:

$$
\begin{aligned}
& H_{o}: \mu_{1}, \mu_{2}, \mu_{3}, \mu_{4}, \ldots, \mu_{n}=0 \\
& H_{o}: \lambda_{1}, \lambda_{2}, \lambda_{3}, \lambda_{4}, \ldots, \lambda_{n}=0
\end{aligned}
$$

Table 1.2: Lagrange Multiplier (LM) and Likelihood Ratio (LR) Tests for the Presence

\begin{tabular}{|c|c|c|c|c|c|c|}
\hline & OLS & $\begin{array}{r}\text { Spatial } \\
\mathrm{FE} \\
\end{array}$ & $\begin{array}{r}\text { Time-period } \\
\text { FE }\end{array}$ & $\begin{array}{c}\text { Spatial \& } \\
\text { Time-period FE }\end{array}$ & $\begin{array}{c}\text { Spatial } \\
\text { (Joint Significance) }\end{array}$ & $\begin{array}{c}\text { Time-period } \\
\text { (Joint Significance) }\end{array}$ \\
\hline LM Lag(Robust) & 0.0002 & 0.1338 & 0.0003 & 0.6207 & & \\
\hline LM Error (Robust) & 0.0000 & 0.1171 & 0.0000 & 0.7390 & & \\
\hline LR Test & & & & & 0.0000 & 0.1208 \\
\hline
\end{tabular}
of Spatial-and Time-Fixed Effects

FE denotes Fixed Effects.

Looking at the results of Table 1.2, the most appropriate model is one including just the time fixed effects.

The next step for any spatial econometric analysis is to determine whether to choose the SAR, SEM, or SDM model. Following Elhorst (2010), I employ the standard LM tests to determine whether either the SAR or SEM model is appropriate the most. The LM lag test checks whether there is spatial dependence in the dependent variable, whereas, the LM error test checks whether there is spatial dependence in the error term. Estimates of the SDM are used to generate a LR to determine whether SAR or SEM should be used instead of the SDM. In order to do this, the following hypotheses are tested:

$$
\begin{gathered}
H_{o}: \theta=0 \\
H_{o}: \theta+\rho \beta=0
\end{gathered}
$$


where $\theta$ and $\beta$ are the same as in Equation 1.1. Both tests are one-way tests. Hence, they only test the specific type spatial dependency one is accounting for. For example, LM Lag test only accounts for spatial dependency in the dependent variable while the LM Error test only accounts for spatial dependency in the error term. The robust LM tests, however, take into account the other type of spatial dependency as well. For instance, LM Lag Robust test also takes into account spatial dependency in the error term. Likewise, the LM Error Robust test takes into account spatial dependency in the dependent variable. Both tests follow a chi-squared distribution with one degree of freedom.

Equation 1.4 tests the hypothesis whether SDM can be reduced to SAR. Equation 1.5 tests whether SDM can be reduced to SEM. SDM is the most appropriate model to use if both hypotheses are rejected. However, if $H_{o}: \theta=0$ is not rejected, then SAR is the most appropriate model if the robust LM tests point towards SAR. Likewise, if $H_{o}: \theta+\rho \beta=0$ is not rejected, SEM is the most appropriate model if the robust LM tests point towards SEM. SDM is used if one of the conditions are not met.

Table 1.3 reports the test statistics of the LM Lag and LM Error tests. As both $H_{o}: \theta=0$ and $H_{o}: \theta+\rho \beta=0$ are rejected, the most appropriate model choice is the SDM. In addition, LeSage and Pace (2009) make the point that if one believes that there are spatially correlated omitted variables in the model and that these omitted variables are correlated with an explanatory variable included in the model, SDM is the most appropriate model to use. Since unseen network effects might exist between states which could be spatially related (which is captured by the error term) and can also affect, for instance, wine or beer contributions, I believe that SDM is the most appropriate model to use. ${ }^{6}$

To fully understand the effects of the explanatory variables in the SDM, it is imperative to have an understanding of how the beta coefficient is interpreted. In SDM, unlike in a regular linear model, $\beta$ does not only represent the marginal effects,

\footnotetext{
${ }^{6}$ I exclude Alaska and Hawaii since they do not have contiguous neighbors. The weight matrix employed is a $\mathrm{k}$-nearest-neighbor $\mathrm{W}$ matrix.
} 
Table 1.3: Lagrange Multiplier (LM) and Likelihood Ratio(LR) Tests for the Presence of Spatial-and Time-Fixed Effects

\begin{tabular}{lrrr}
\hline & LM Values & p-value & Model Choice \\
\hline SDM vs SAR & $67.7461^{* * *}$ & 0 & SDM \\
SDM vs SEM & $60.6369^{* * *}$ & 0 & SDM \\
\hline *** denotes statistical significance at the $1 \%$ &
\end{tabular}

level.

meaning- an increase in $\beta$ not only captures the explanatory variable changes and how it affects the dependent variable, but now captures the average direct, average indirect, and average total effects (LeSage and Pace, 2009), which they term effects estimates. Since models with a spatially-lagged dependent variable have estimates that are hard to interpret, the data generating process in reduced form for such models (in this case, SDM) can be mathematically written as ${ }^{7}$ :

$$
\begin{aligned}
y & =\rho W y+X \beta+W X \theta+\varepsilon \\
y & =\left(I_{n}-\rho W\right)^{-1}(X \beta+W X \theta)+\left(I_{n}-\rho W\right)^{-1} \varepsilon \\
\left(I_{n}-\rho W\right)^{-1} & =I_{n}+\rho W+\rho^{2} W^{2}+\cdots+\rho^{q} W^{q} \\
S_{r}(W) & =\frac{\partial y}{\partial x_{r}}=\left(I_{n}-\rho W\right)^{-1}(\beta+W \theta)
\end{aligned}
$$

The "r" subscript in the $S_{r}(W)$ represents individual explanatory variable in the $X$ matrix.

In $\mathrm{SDM}, S_{r}(W)$ is intended to capture the average direct, average indirect and, average total effects of the change in a variable on the dependent variable and can be mathematically shown as follows:

$$
\begin{gathered}
\text { Average Direct Effect }: \frac{\partial \mathrm{E}\left(\mathrm{y}_{\mathrm{i}}\right)}{\partial x_{i r}}=S_{r}(W)_{i i} \\
\text { Average Indirect Effect }: \frac{\partial \mathrm{E}\left(\mathrm{y}_{\mathrm{i}}\right)}{\partial x_{j r}}=S_{r}(W)_{i j} \text {. }
\end{gathered}
$$

\footnotetext{
${ }^{7}$ The following equations follow directly from Equation (1.1)
} 
The meaning of average direct effects can be interpreted as follows. For example, if Wine of state $i$ is changed, how does it affect the Tax in state $i$ ? This is called $i$ 's own effects. However, average direct effect also captures spillover effects, in which the change in Wine in state $i$ affects Wine in its neighboring state $j$, which, again, "feeds back" to state $i$. This is called the feedback effect. The average of the diagonal

elements of the $S_{r}(W)$ matrix captures both, own effect and the feedback effect, and is called the average direct effect.

The average indirect effect captures spillovers effects of a change in an explanatory variable in state $i$ and how that affects observations in neighboring state $j$, where state $i$ and $j$ are not same. This effect is captured by the average of the off-diagonal elements of the $S_{r}(W)$ matrix. Since the indirect effects are cumulated over all neighbors, its magnitude is usually larger than the direct effects. Finally, the average total effect is the summation of the average direct effect and the average indirect effect.

The advantage of using the SDM panel is twofold. First, it provides effect estimates that account for spatial dependence in the dependent variable, which is a much richer set of results that non-spatial panel model do not capture because they assume independence among observations. The $\rho$ parameter captures this in this study. As data shows neighboring states changing their excise tax rates, not accounting for spatial dependence if it is present results in incorrect estimates (LeSage and Dominguez, 2012). Second, the SDM is not restricted to have the same sign effect estimates, which the SAR model does (Elhorst, 2010).

\subsection{Empirical Results and Robustness Checks}

Table 1.4 reports the results of the effect of wine-industry campaign contributions to officials running for state offices on state wine excise tax rates. It consists of the average direct, average indirect, and average total effects estimates from the panel data SDM. The key finding is that the $\rho$ parameter is statistically significant at the $1 \%$ level and is positive. The statistical significance of $\rho$ establishes that state wine 
excise taxes are spatially correlated. The table also shows that the major variables of interest, Wine and Beer, are as expected and that Wine is statistically robust at the $5 \%$ level. In addition, 6 out of the 8 variables used in the study are statistically significant.

The results show that an increase in Wine in a state decreases Tax and has a negative average direct, indirect, and total effect. The results show that a dollar per 100 residents increase in Wine leads to a 6 -cent decrease in Tax in a said state, a 14-cent tax decrease in surrounding states, and a 21-cent excise tax decrease overall. The direct and total effects are statistically significant at the $5 \%$ level, whereas, the indirect effect is significant at the $10 \%$ level.

However, only the indirect effect and total effect are economically significant when there is a change in Wine. For example, one standard deviation increase in Wine $(0.79)$ in a said state decreases wine excise tax by only 5 -cents $(0.79 \times-0.0675)$ or only about ten percent $(-0.0533 / 0.51)$ of a one standard deviation of the dependent variable. The average indirect and total effects are economically significant, however. The indirect effect approximately is $23 \%(0.79 \times-0.1462 / 0.51)$ and the total effect is approximately $33 \%(0.79 \times-0.2136 / 0.51)$ of one standard deviation in the dependent variable. Additionally, standard deviation of 0.79 for Wine would turn Virginia in 2012 (\$0 in campaign contributions per 100 residents) to North Carolina in 2012 (\$0.20 in campaign contributions per 100 residents).

Since beer and wine can be considered as substitutes for one another, it can be hypothesized that higher amounts of campaign contributions from the beer industry in a state would earn political favors for the beer industry and possibly lead to an increase in wine excise taxes for any given amount of government spending. The signs for the average direct, indirect, and total effects of Beer on Tax are as expected. The results show that a dollar increase per 100 residents in Beer results in a 16-cent increase in wine excise taxes overall. The effect is statistically significant at the $5 \%$ level. While direct effects for Beer does not have much economic significance $(1.07 * 0.0357 / 0.51)$, or about $7 \%$ of one standard deviation of Tax, its economic significance for indirect 
and direct effects is high. For example, one standard deviation increase in Beer (1.07) in surrounding states increases wine excise tax by 14 -cents $(1.07 \times 0.1302)$ in a said state or is approximately $27 \%$ of one standard deviation in Tax. The total effects is a 18 -cents $(1.07 \times 0.1659)$ increase or is approximately only about $35 \%$ of the standard deviation in Tax overall.

Gov_Term, Citizen, Pop65, and Popwhite have total effects signs as expected. A positive Citizen total effects sign is consistent with the expectation that states leaning towards a more liberal ideology favor higher taxes on wine. Growth_Rate and Health are expected to have positive total effects estimates but have surprising negative signs.

As a robustness check, I conducted spatial analysis using only 44 states (excluding the 4 control states) in the mainland United States, reported in Table 1.5. The main finding of this robustness check is that $\rho$ parameter possesses the same sign as $\rho$ in Table 1.4, and is also significant at the $1 \%$ level. This finding is especially important because it establishes an existence of a spatial correlation, even while controlling for "control" states. The effect estimates are also similar. The signs of the major variables of interests are the same as in Table 1.4. The statistical significance of the Wine direct effect stays the same. However, the statistical significance of Wine indirect effect increases and is now significant at the $5 \%$ level. Wine total effects is statistically robust at the $1 \%$ level. Citizen loses significance and so does Health. The sign for Citizen is not as expected. However, it is so for Health.

Additionally, I also conducted a spatial analysis using 5-nearest-neighbor weight matrix. I hypothesize rho to lose spatial significance when using a 5-nearest-neighbor weight matrix. This assumption is reasonable because the further out states are from a given state, the less impact they would have on that state. This result is reported in Table 1.6.

The results show that the $\rho$ parameter indeed loses significance. However, Wine and Beer still hold expected signs but are not statistically robust. The signs for Health and PopWhite are the same as before. However, Gov_Term possesses a 
Shree B. Pokharel Chapter 1. Campaign Contributions and Wine Excise Taxes 17

contradictory negative sign. All variables lose significance in this specification except for PopWhite.

\subsection{Conclusion}

Given the growing importance of the wine industry for the US, increases in campaign contributions from the wine industry to officials running for state offices, along with theoretical and empirical evidence that shows that tax rates are interdependent, I hypothesized that the wine-industry special interest influences state wine excise taxes across space. I find that there is robust statistical evidence that wine excise taxes exhibit spatial dependence, which is the key finding of this study. I find that, on average, the increases in campaign contributions from the wine industry in a state results in a decrease in wine excise taxes in the given state and its neighboring states.

There are two contributions of this study. First, it is the first study to look at the effects of campaign contributions of the alcohol industry, specifically, the wine industry on state wine excise taxes. Previous special interest group literature have looked at the tobacco industry, for instance. Second, it is also the first study to look at the wine industry using a spatial econometric model. One of the distinguishing and important ability of spatial econometric models is that they can empirically test for the presence of spatial dependency and quantify spillover effects. In context of this paper, the use of SDM showed the reader that there is robust statistical evidence of spatial dependency in wine excise taxes between states. Not accounting for these indirect effects when they clearly are present could provide biased estimates. Therefore, one application of spatial models is that given its ability to test for spatial dependence, policymakers and economists should account for spillover effects while making informed policy proposals.

Moving forward, future projects could look at establishing a causal relationship between wine production and wine excise taxes across time once production data for all fifty states become available. In addition, research could look at the political 

economy of campaign contributions in future. One example could be to look at the channels through where these effects take place. For instance, looking at which state offices most likely influence decisions could be a starting point. 
Shree B. Pokharel Chapter 1. Campaign Contributions and Wine Excise Taxes 19

Table 1.4: The Effect of Wine-Industry Campaign Contributions on Wine Excise Taxes for 48 Contiguous US States Using 4-Nearest-Neighbor Matrix

\begin{tabular}{|c|c|c|c|c|c|c|c|c|}
\hline Variable & Direct & Effects & Variable & Indirect & Effects & Variable & Total E & ffects \\
\hline Wine & -0.0675 & $* *$ & Wine & -0.1462 & $*$ & Wine & -0.2136 & $* *$ \\
\hline Beer & 0.0357 & & Beer & 0.1302 & $* *$ & Beer & 0.1659 & $* *$ \\
\hline Gov_Term & 0.0731 & & Gov_Term & -0.0397 & & Gov_Term & 0.0334 & \\
\hline Citizen & 0.0036 & $* *$ & Citizen & 0.0032 & & Citizen & 0.0068 & $* *$ \\
\hline Gr_Rate & 0.0011 & & Gr_Rate & -0.0059 & & Gr_Rate & -0.0048 & \\
\hline Health & -0.0009 & $* * *$ & Health & -0.0027 & $* * *$ & Health & -0.0035 & $* * *$ \\
\hline Pop65 & 0.118 & $* * *$ & Pop65 & -0.1946 & $* * *$ & Pop65 & -0.0766 & $*$ \\
\hline PopWhite & -0.0114 & $* * *$ & PopWhite & -0.0159 & $* *$ & PopWhite & -0.0273 & $* * *$ \\
\hline rho & 0.173 & $* * *$ & & & & & & \\
\hline $\mathrm{R}$ - squared & 0.339 & & & & & & & \\
\hline
\end{tabular}

Note: Dependent variable is the state wine excise tax. ${ }^{*}, * *$, and ${ }^{* * *}$ denote statistical significance at the 10,5 , and $1 \%$ levels, respectively. 
Shree B. Pokharel Chapter 1. Campaign Contributions and Wine Excise Taxes 20

Table 1.5: The Effect of Wine-Industry Campaign Contributions on Wine Excise Taxes for 44 Contiguous US States Using 4-Nearest-Neighbor Matrix

\begin{tabular}{|c|c|c|c|c|c|c|c|c|}
\hline \multirow{2}{*}{$\begin{array}{l}\text { Variable } \\
\text { Wine }\end{array}$} & \multicolumn{2}{|c|}{ Direct Effects } & \multirow{2}{*}{$\begin{array}{l}\text { Variable } \\
\text { Wine }\end{array}$} & \multicolumn{2}{|c|}{ Indirect Effects } & \multirow{2}{*}{$\begin{array}{l}\text { Variable } \\
\text { Wine }\end{array}$} & \multicolumn{2}{|c|}{ Total Effects } \\
\hline & -0.0667 & $* *$ & & -0.1882 & $* *$ & & -0.2550 & $* * *$ \\
\hline Beer & 0.0142 & & Beer & 0.1567 & $* * *$ & Beer & 0.1709 & $* * *$ \\
\hline Gov Term & 0.0597 & & Gov Term & -0.1555 & & Gov Term & -0.0959 & \\
\hline Citizen & -0.0009 & & Citizen & -0.0006 & & Citizen & -0.0016 & \\
\hline Gr_Rate & -0.0008 & & Gr_Rate & -0.0039 & & Gr_Rate & -0.0047 & \\
\hline Health & 0.0000 & & Health & 0.0017 & & Health & 0.0017 & \\
\hline Pop65 & 0.1081 & $* * *$ & Pop65 & -0.2626 & $* * *$ & Pop65 & -0.1545 & $* *$ \\
\hline PopWhite & -0.0034 & & PopWhite & -0.0194 & $* * *$ & PopWhite & -0.0228 & $* * *$ \\
\hline rho & 0.2270 & $* * *$ & & & & & & \\
\hline R-Squared & 0.3829 & & & & & & & \\
\hline
\end{tabular}

Note: Dependent variable is the state wine excise tax. ${ }^{*},{ }^{* *}$, and ${ }^{* * *}$ denote statistical significance at the 10,5 , and $1 \%$ levels, respectively. 
Shree B. Pokharel Chapter 1. Campaign Contributions and Wine Excise Taxes 21

Table 1.6: The Effect of Wine-Industry Campaign Contributions on Wine Excise Taxes for 48 Contiguous US States Using 5-Nearest-Neighbor Matrix

\begin{tabular}{|c|c|c|c|c|c|c|c|}
\hline Variable & Direct & Effects & Variable & Indirect & Effects & Variable & Total Effects \\
\hline Wine & -0.0526 & $*$ & Wine & -0.0204 & & Wine & -0.0729 \\
\hline Beer & 0.0332 & & Beer & 0.0562 & & Beer & 0.0893 \\
\hline Gov Term & 0.0645 & & Gov Term & -0.1231 & & Gov Term & -0.0586 \\
\hline Citizen & 0.0020 & & Citizen & -0.0045 & & Citizen & -0.0025 \\
\hline Gr_Rate & 0.0005 & & Gr_Rate & -0.0005 & & Gr_Rate & 0.0001 \\
\hline Health & -0.0003 & & Health & -0.0009 & & Health & -0.0012 \\
\hline Pop65 & 0.1244 & $* * *$ & Pop65 & -0.1072 & $* * *$ & Pop65 & 0.0172 \\
\hline PopWhite & -0.0096 & $* *$ & PopWhite & -0.0155 & $* *$ & PopWhite & -0.0250 \\
\hline rho & 0.0800 & & & & & & \\
\hline R-Squared & 0.2909 & & & & & & \\
\hline
\end{tabular}

Note: Dependent variable is the state wine excise tax. ${ }^{*},{ }^{* *}$, and ${ }^{* * *}$ denote statistical significance at the 10,5 , and $1 \%$ levels, respectively. 


\section{Chapter 2}

\section{State Exit Exams and Graduation Rates: A Hierarchical SLX Modelling Approach}

\section{$2.1 \quad$ Introduction}

The widespread consensus that high school diplomas displayed low academic skills and standards in the latter half of the twentieth century led to policies favoring highstakes school exit exams in the US. The deficiency of job skills and college preparedness in high school graduates were mostly attributed to "social promotion" (Reardon and Galindo, 2002) and to "watered-down" curriculum (Bond and King, 1995). This view was supported when evidence of students' lack of proficiency in primary subjects were compared to those of other countries during the Cold War era and was further emphasized with the publication of $A$ Nation at Risk: The Imperative for Educational Reform (Warren et al., 2006).

The Nation at Risk report published in 1983 stated that "the educational foundations of our society are presently being eroded by a rising tide of mediocrity that threatens our very future as a Nation" and that "more and more young people emerge from high school ready neither for college nor for work" (Gardner, 1983). As a re- 
mediation measure, the report also recommended, among other things, "high-stakes standardized tests of measuring achievement" and that it "should be administered at major transition points from one level of schooling to another and particularly from high school to college or work" (Gardner, 1983). These exams are considered "high stakes" "if they carry serious consequences for students or for educators" (AERA, 2017). For students, these exams are considered high stakes because failing these exams might act as an impediment to receiving their diplomas. For educators, it might bring public scrutiny and less financial rewards.

Widespread implementation of these high-stakes exit exams by US states started as early as 1980s and has increased over time. Fourteen states enforced these exams in 1990 and the number grew to 18 in 2000 (Warren et al., 2006). As of 2013, 23 out of 50 US states have implemented this policy (Ed Counts Research Center, 2017). Figure 2.1 shows states with and without state exit exams in 2013. The color grey represents states without the state exit exam requirement, whereas, the color black represents states with state exit exam requirement.

Figure 2.1: States with and without State Exit Exams

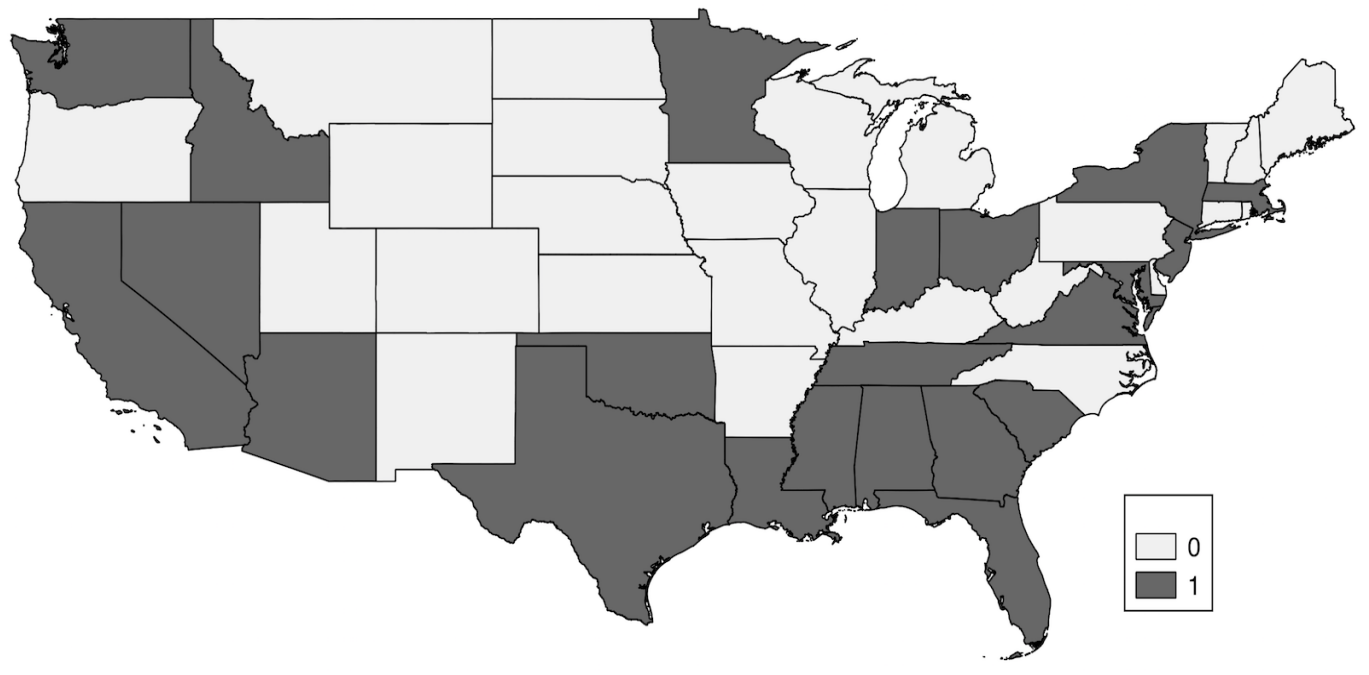

Source: Ed Counts Research Center (2017).

The stated goal of these exams was to encourage students and school districts to 
demonstrate that they had achieved competency in certain areas prior to graduation. Theoretically, the effect of exit exams on graduation rates is ambiguous. Exit exams could combat social promotion by some districts, leading to a lower graduation rate. On the other hand, the stigma and competitive effect of reported statewide exam scores could lead to an increase in graduation rates.

Much research has been done on the effect of these exit exams on educational outcomes such as high school completion rates, dropout rates and dropout likelihood, earnings, and graduation rate. Greene and Winters (2004), Warren and Jenkins (2005), and Warren et al. (2006) found no effect of state exit exams on high school completion rates. Warren and Edwards (2005) show no effect of high school exit exams on dropout rates. Contrastingly, Hemelt and Marcotte (2013) report high school exit exams to positively increase dropout rates between 12th graders. Beardsley and Berliner (2002) found an increase in dropout rates, Papay et al. (2010) found to have a negative influence, whereas $\mathrm{Ou}$ (2010) found mixed results. Warren et al. (2008) report no effect of high school exit exams on earnings.

In terms of graduation rates, studies such as Beardsley and Berliner (2002) and Marchant and Paulson (2005) found state exit exams to negatively affect graduation rates. Baker and Lang (2013) found no statistically significant effect of high school exit exams on graduation rates. While Beardsley and Berliner (2002)'s study was a qualitative study, Marchant and Paulson (2005)'s and Baker and Lang (2013)'s study was quantitative. However, these studies only take state factors into account without accounting for school districts that are embedded within states.

While these studies look at the impact of high-stakes exit exams on graduation rates, they do not empirically account for the embedded nature of school districts in state education systems. Additionally, school districts have spatial spillovers in terms of policies, teacher labor markets, and student flows. For example, one district in a region raising teacher salaries will likely influence other districts to raise their salaries or risk losing teachers on the margin. Hanushek (1986) is a seminal paper on education production functions, and we begin our study with his work. However, no 
studies to date have empirically accounted for spatial spillovers across school districts and also their embedded nature in the education literature. We intend to fill this gap. In this paper, we do so by employing a Bayesian Hierarchical SLX model. While we find that non-spatial papers miss important spatial spillovers across school districts, we find no statistically significant evidence that states with exit exams have higher or lower graduation rates than states without such exams.

There are major advantages of using a hierarchical model. First, these models help to represent data structures that are close to the real world. These models help to separate individual effects, in the case of this study, school-district level effects on high school graduation rates, from the state level effects. This makes it a closer representation of the real world data structure than a normal linear model. Second, by acknowledging that Ordinary Least Squares (OLS) violates the independence assumption in hierarchical data, it helps correct biased estimates that OLS doesn't. In our case, OLS would take the school districts within a same state as independent from one another, when they clearly are not as they have to take the same state exit exam. This is one of the main identifying features of this paper compared to previous studies in that it takes this key violation into account. Third, it allows for the use of state-level variables to control for state-level variation in policy, in this case whether or not there is a state exit exam. In the case of this research, we have 8,636 school districts that are nested within 46 US states.

There are two contributions of this paper. First, by taking into account the hierarchical structure of data in its natural state, we capture the school-district level as well as the state-level influences on high school graduation rates. Second, we contribute to the literature by also capturing spatial spillovers that previous nonspatial research did not account for.

The remainder of the paper proceeds as follows. Section 2 describes the empirical specification and statistical methodology used in this paper. Section 3 describes the data in detail. Section 4 describes the results and Section 5 concludes. 
Hall, Lacombe, Pokharel Chapter 2. A Hierarchical SLX Modelling Approach 26

\subsection{Statistical Methodology}

\subsubsection{Hierarchical Models}

In their natural states, some data have a hierarchical structure to them. For example, students nested within a classroom, counties nested within states, and school districts nested within states. Hierarchical structure violates the independence assumption since school districts within the same states are exposed to the same set of state laws. In case of this study, school districts within a state are affected by a state exit exam, hence, violating the independence assumption as they are exposed to the same set of information. If not used in their natural state, data can provide biased estimates.

In addition to the three advantages mentioned in the previous section, using hierarchical models have at least two more benefits. Fourth, it accounts for the fact that multilevel models nest classical regression models and, therefore, accounts that each upper level unit intercept is different (intercept of each state in our paper) but also have some similarities. To explain this concept more clearly, we refer to Gelman and Hill (2006) who state that "classical regression model can be viewed as special cases of multilevel models." Here, $\alpha_{j} \sim N\left(\mu_{\alpha}, \sigma_{\alpha}\right)$. Ignoring any heterogeneity and assuming a common intercept for all "upper-level" units (i.e., 46 separate states in our paper), the first model is called a fully-pooled model. It assumes that all states are homogeneous and should have a common intercept. On the other hand, a no-pooling model assumes heterogeneity among the states and allows for including a dummy variable for each state. Basically, this model allows all 46 states in our paper to be different from one another.

To explain this further, the matrix form of hierarchical SLX model representation is given by the following equations: 


$$
\begin{aligned}
\text { Level1: } & y=X \beta+\Delta \alpha+\varepsilon \\
\text { Level2: } \quad & \alpha=Z \gamma+u \\
& \varepsilon \sim N\left(0, \sigma^{2} I_{n}\right) \\
& u \sim N\left(0, \tau^{2} I_{j}\right)
\end{aligned}
$$

where at Level 1, $y$ is the $N \times 1$ vector of observations and represents the dependent variable. $X$ represents the matrix of explanatory variables at Level 1 and has a $N \times k$ dimension. The $\beta$ is a $k \times 1$ vector of coefficients associated with $X$. $\alpha$ represents the $J \times 1$ vector of intercepts from Level 2. $\varepsilon$ is the error term associated with Level 1 and is normally distributed with a 0 mean and variance of $\sigma^{2} I_{n}$ and has a $N \times 1$ dimension.

At Level 2, as mentioned above, $\alpha$ represents the $J \times 1$ vector of individual intercepts (state-level intercepts in our study) and is the dependent variable. $Z$ is the vector of explanatory variables (that also includes a constant term) with dimension $J \times m . \gamma$ is a $J \times m$ vector of coefficients associated with the $Z$ term. $u$ is the error term in Level 2 and is normally distributed with a 0 mean and variance of $\sigma^{2} I_{n}$ and has a $J \times 1$ dimension. As is standard in hierarchical models, we assume that $\varepsilon$ and $u, u$ and $X$, and $u$ and $Z$ are not correlated (Raudenbush and Bryk, 2002).

This model is also called an "intercepts-as-outcome" model. It is called so because the "Level 2 equation has the Level 1 intercept as its dependent variable (as its outcome)" (Adewale et al., 2007). It is also called a "random intercepts" model. Understandably, it is also called so as for each state, it sets a baseline of graduation rates. The individual school districts' graduation rates then varies around this baseline for the state it is embedded in due to, for instance, differences in spending per pupil.

Gelman and Hill (2006) argue that data could estimate the level 2 error variance and that they "see no reason (except for convenience) to accept estimates that arbi- 
trarily set this parameter to one of these two extreme values." Here, we can assume that each state is different but also share similarities (Lacombe and Flores, 2017).

Fifth, it corrects for any potential bias that might arise from choosing either only the "fully-pooled" model or the "non-pooling" models. Intercepts in a hierarchical model are a linear combination of the "fully-pooled" model and "no-pooling" model and can be written as (Subramanian, 2010; Luke, 2004):

$$
\begin{aligned}
\hat{\alpha}_{j}^{E B} & =\lambda_{j} \hat{\alpha}_{j}^{N P}+\left(1-\lambda_{j}\right) \hat{\alpha}^{F P} \\
\lambda_{j} & =\frac{\tau^{2}}{\left(\tau^{2}+\sigma^{2} / n_{j}\right)}
\end{aligned}
$$

where, $\hat{\alpha}_{j}^{N P}$ represents the "no-pooling" intercept estimate, $\hat{\alpha}_{j}^{F P}$ represents the "fully-pooled" intercept estimate, and $\hat{\alpha}_{j}^{E B}$ represents the "empirical Bayes" or "shrinkage" estimate of the linear combination of the "no-pooling" and the "fully-pooled" models. $\lambda_{j}$ represent the weights assigned to each aforementioned models and are a function of both level error variance (ie., variance of the school-district level and the state level ) and, $n_{j}$, the number of level 1 observation in each level 2 unit.

The empirical Bayes works in the following manner. If $n_{j}$ is small, $\lambda_{j}$ is small, which means that $\hat{\alpha}_{j}^{E B}$, the empirical Bayes, moves close towards the fully-pooled estimate, $\hat{\alpha}_{j}^{F P}$. Similarly, if $n_{j}$ is large (such as the number of school districts in the state of Texas, ie., 745 in our sample), $\lambda_{j}$ is large, which means that $\hat{\alpha}_{j}^{E B}$, the empirical Bayes, moves closer towards the no-pooling estimate, $\hat{\alpha}_{j}^{N P}$. Here, more weight is placed on the "no-pooling" intercept estimate. Hence, the advantage in using the empirical Bayes is that it corrects for any possible bias from choosing either "no-pooling" or "fully-pooled" model at random.

We now extend this basic intercept hierarchical model by adding a spatial factor to it. We use the Spatial Lag of X (SLX) model at both levels of the hierarchy. A SLX model provides a much richer set of results as it allows for local spillovers. As 
it includes spatially-lagged independent variables (which capture local spillovers), it calculates the direct effects (own effects) as well as the indirect effects. The direct (own) effects calculate the effects of the explanatory variables on the dependent variables; the indirect effects (spillover effects) capture the effect of neighbors on the dependent variable.

\subsubsection{The Hierarchical SLX Model}

The matrix form of hierarchical Spatial Lag of X model representation is given by the following equations:

$$
\begin{array}{rlrl}
\text { Level1 : } & y & =X \beta+W_{1} X \theta+\Delta \alpha+\varepsilon \\
\text { Level2 }: & \alpha & =Z \gamma+W_{2} Z \delta+u \\
& \varepsilon \sim N\left(0, \sigma^{2} I_{n}\right) \\
& u \sim N\left(0, \tau^{2} I_{j}\right)
\end{array}
$$

where at Level 1, $y$ is the $N \times 1$ vector of observations and represents the dependent variable. $X$ represents the matrix of explanatory variables at Level 1 and has a $N \times k$ dimension. The $\beta$ is a $k \times 1$ vector of coefficients associated with $X$. The difference between the previous model and this model is the addition of the $W_{1} X$ matrix and is what makes this model a spatial econometric one. $W_{1} X$ is a spatially-weighted explanatory variable matrix. Here, $W_{1}$ is a row-stochastic spatial weight matrix with $N \times N$ dimension. $\theta$ is a $k \times 1$ vector of coefficients associated with the $W_{1} X$ term. $\alpha$ represents the $J \times 1$ vector of intercepts from Level 2. $\varepsilon$ is the error term associated with Level 1 and is normally distributed with a 0 mean and variance of $\sigma^{2} I_{n}$ and has a $N \times 1$ dimension.

At Level 2, as mentioned above, $\alpha$ represents the $J \times 1$ vector of individual intercepts (state-level intercepts in our study) and is the dependent variable. $Z$ is the vector of explanatory variables (that also includes a constant term) with dimension 
$J \times m . \gamma$ is a $J \times m$ vector of coefficients associated with the $Z$ term. Again, as before, the addition of spatially-weighted explanatory variable matrix $W_{2} Z$ with $J \times m$ dimension makes this model a spatial econometric one at this level. $\delta$ is a $m \times 1$ vector of coefficients associated with the $W_{2} Z$ term and $\delta$ can be thought of as a matrix of dummy variables that can be used in a standard fixed effects model. $u$ is the error term in Level 2 and is normally distributed with a 0 mean and variance of $\sigma^{2} I_{n}$ and has a $J \times 1$ dimension. As is standard in hierarchical models, we assume that $\varepsilon$ and $u, u$ and $X$, and $u$ and $Z$ are not correlated (Raudenbush and Bryk, 2002).

We use Bayesian econometrics for our analysis. In this method, we make inferences based on posterior distribution of the parameters. For readers not familiar with Bayesian econometrics, the following equation represents the posterior distribution of parameters:

$$
\pi(\theta, \alpha \mid y) \propto f(y \mid \theta, \alpha) f(\alpha \mid \theta) \pi(\theta)
$$

In normal posterior distributions, the posterior distribution is proportional to the likelihood times the priors. Since we are estimating a hierarchical model, Equation 2.9 shows that the posterior distribution is proportional to the likelihood times the priors of the parameters times the hierarchical prior. The priors used in this study are independent, hence, can be multiplied with one another. They are also proper priors and also are conjugates. Priors for $\beta$ and $\gamma$ are multivariate normal whereas priors for $\sigma^{2}$ (Level 1 error variance) and $\tau^{2}$ (Level 2 error variance) are inverseGamma. Since we use uninformative values even though we use proper priors, we use a multivariate normal prior of mean $0_{K}$ vector and covariance $1000 \times I_{K}$ for $\beta$ and $\gamma$ where $K$ represents the number of explanatory variables used in the study. The shape and scale parameters for the inverse-Gamma priors for both levels error terms are set to 0.001 .

We rely on a Gibbs sampling method to obtain our estimates since obtaining 
closed form solutions of the parameters analytically can only occur under special circumstances. Since the Gibbs sampler only requires that the conditional distributions be available, and in our case it is available since we are using the SLX model, we rely on this method to get estimates.

The model we are estimating in this study is a local spatial econometric model. It is one among the two types of spatial econometric models, the other one being a global model. In a local model, spillovers in the independent variables are allowed. In case of our study, they are represented by the $W X$ and $W Z$ terms. Unlike a local model, global model, however, also contains a $W y$ term in addition to $W X$ and $W Z$, allowing the spillover effect to disseminate across the entire sample.

We use a local spatial econometric model because school districts are closely situated to each other and it is unlikely that any spillovers are going to propagate across the entirety of the United States. It is most likely to be contained within a specific geographical range. In addition, we use a local model because the structure of our data is hierarchical in its natural state. Since each state is different in terms of socioeconomic factors, allocating all states as homogeneous would lead to biased estimates of graduation rates. Moreover, local spillovers are a common occurrences in modelling regional patterns than global spillovers (LeSage, 2014). To put this statement in perspective in relation to our study, one would assume graduation rates in a given school district in Maine to be affected by its close neighbors than to be influenced by school districts in Florida.

In addition, the coefficients of local spillovers models as the SLX used in this study are easy to interpret as compared to global models such as the Spatial Durbin Model (SDM). In our model, all the coefficients have a straightforward interpretation. In Level 1, $\beta$ represents its own partial derivative (direct effects) and $\theta$ represents the cross-partial derivatives (indirect/spillover effects). The total effect is represented by $\beta+\theta$. In Level2, $\gamma$ represents the direct effect and $\delta$ represents the indirect effect. The total effect is represented by $\gamma+\delta$. 


\subsection{Data}

\subsubsection{Level 1 Data}

At the school district level, i.e., Level 1, we use high school graduation rates as the dependent variable. The dependent variable is the high school graduation rate of public school districts of 46 US states and excludes charter schools and private schools. There are 8,636 individual school districts in our study. Since it is a spatial econometric exercise, we exclude Alaska and Hawaii in our calculation as they have no contiguous neighbors. We also do not capture school districts in Oklahoma and Pennsylvania due to the lack of availability of data from our source. The data for graduation rates is obtained from The Hechinger Report. The Hechinger Report is an independent news outlet which focuses on education, particularly inequality and innovation.

High school graduation rates have been a subject of debate in the education literature. Heckman and LaFontaine (2010) report that graduation rates differ from anywhere between $66 \%$ to $88 \%$ depending on the definition, sources, or methods used. The definition of high school graduation rates differ from "dividing the number of public high school diplomas by an estimate of the number of students who would have received diplomas that year if graduation rates were 100 percent" (Greene, 2001) to the government mandated Four-year Adjusted Cohort Graduation Rate (ACGR) implemented by the U.S. Department of Education. The ACGR is calculated "as the number of students who graduate in four years with a regular high school diploma divided by the number of students who entered high school four years earlier (adjusting for transfers in and out, migrs and deceased students." (US Department of Education, 2017) Despite the differences in measures of calculating high school graduation rates, we use the government mandated definition and rates as they provide with a uniform measure across all school districts.

As mentioned before, in his seminal paper, Hanushek (1986) proposed inputs to schooling outcomes as education production function. Following Hanushek (1986) 
for categorization of inputs, the school-district level explanatory variables used in this study that are likely to affect graduation rates are categorized as Family Inputs, School Inputs, and Peer Input. The choice of explanatory variables are standard variables used in education literature (Hanushek et al., 2009). In this study, lmeanhhinc and lwifeyeshusno fall under the Family Inputs category. lmeanhhinc is the mean household income of children that are enrolled in a specific school district in 2012 inflation-adjusted dollars and is log transformed. Hall and Leeson (2010) find a negative relationship between mean-median income ratio and school performance. lwifeyeshusno represent number of children that are enrolled in a specific school district coming from a single parent household (where the mother is present but not the father), and is also log transformed. Palardy (2013) found traditional family structure (consisting of both parents in the household) to positively affect high school graduation rates.

In addition to Family Inputs, there are School Inputs that are likely to affect high school graduation rates. The variables that fall under this category are linstrucsalpp, stratio, locrevpercent, and lexpperpupil. Instructional salary per pupil is the authors' calculation and represents expenditures on salaries of instructional staff. It is represented by linstrucsalpp and is log transformed in our calculations. Teacher-student ratio is also hypothesized to have an effect on graduation rates. It is represented by stratio. It is also the authors' calculation, calculated as the number of enrolled students in a public school district divided by the total number of teachers in the school. Reardon and Galindo (2002) find a negative relationship between studentteacher ratio on dropout rates. locrevpercent is also the authors' calculation and is calculated by dividing total local revenues by the total revenue. Another variable in this category is lexpperpupil which is also the authors' calculation and represents the total expenditure on each pupil in a school district. This variable is log transformed as well for scaling purposes. Jackson et al. (2016) find a positive relationship between increases in per pupil spending and completed years of education.

Finally, racial fractionalization index within a school district is represented by 
Hall, Lacombe, Pokharel Chapter 2. A Hierarchical SLX Modelling Approach 34

racial_frac and serves as a Peer Input. It measures "the probability that two school district residents drawn randomly will be of different races" (Hall and Leeson, 2010). This measure intends to capture the differences in provision of education that might arise due to disagreement over education production that is correlated with race. Hall and Leeson (2010) find a negative relationship between racial fractionalization index and school district performance in Ohio.

\subsubsection{Level 2 Data}

While school-district level explanatory variables can be hypothesized to affect graduation rates of school districts the most, state level policies are also likely to affect those rates because of the hierarchical structure of the data. Therefore, we use state exit exam as our Level 2 variable. It is represented by stexitexam and indexes whether the state requires an exit exam based on 10th grade or higher. It is a dummy variable, with 1 indicating that the state requires state exit exam for its high school students, and 0 , otherwise.

Table 2.1 presents the summary statistics, year of reference, and source for all variables used in this study.

\subsection{Empirical Results}

Tables 2.2 and 2.3 report the results from Level 1 and Level 2 SLX hierarchical models. Specifically, Table 2.2 reports results from school-district level (Level 1) with state exit exams as the Level 2 variable. Table 2.3 reports state exit exam (Level 2) results.

Before interpreting the coefficient estimates, it is of importance to understand how these estimates are calculated in a Bayesian setting. In order to get the marginal distributions of each parameter used in this study, we ran the Gibbs sampling algorithm through the full conditional distribution of each of the parameters in this study. For each model, we ran 100,000 iterations using the Gibbs sampling algorithm to get our 
parameters estimates. However, we discard the first 50,000 iterations as they are in the "burn-in" phase. The rest 50,000 iterations estimate the parameter estimates.

In order to find the statistical significance of the parameters, we also calculate the 95\% credible intervals for each parameter as this is a standard practice in Bayesian analyses. We do so to check whether the $95 \%$ credible interval contains 0 or not. If it does not, then the parameter estimate has a marginal density away from zero, hence, suggesting that the independent variable is statistically significant.

Determining the proper weight of the spatial weight matrix, $W$, is very important to our analysis. For global models such as the SAR or SDM, its effect on the estimates are little as long as LeSage and Pace (2009) recommendation is followed. However, that is not true in the case of local models. Therefore, it is important to determine the "correct" $W$ matrix in order to get correct estimates.

We find the correct $W$ matrix for both levels in the following manner: we compare nine different nearest-neighbor $W$ matrices with neighbors ranging from 2 to 10. Each level consists of a total of 9 different models. Therefore, there are 81 different models to choose from. If they are thought of in a matrix form, in terms of our study, the rows represent school-district level nearest neighbor $W^{\prime} s$ and columns represent the state level nearest-neighbor $W$ matrices. We then use the Deviance Information Criterion statistic (DIC) to choose from the different models to determine the $W$ matrix that is the most appropriate (Spiegelhalter et al., 2002). The DIC statistic with the lowest number is the most appropriate model to use. In our case, $W$ matrix with 10 nearestneighbor at the school-district level (Level 1) and with 2 nearest-neighbors at the state level (Level 2) are the most appropriate spatial weight matrices to use.

\subsubsection{Level 1 Results}

Table 2.2 shows the average direct, indirect, and total effects of Level 1 explanatory variables on high school graduation rates. The results show that most of the variables of interest are statistically significant for all (direct, indirect, and total) effects. 
The direct effects are comparable to previous studies as they represent the raw beta estimates in normal linear models. The own effects (direct effects) of all explanatory variables are statistically significant except for the Teacher Student Ratio variable. Log of Mean Household Income is positively related to graduation rates with a coefficient of 9.1425 . Since this variable is log transformed, a $1 \%$ increase in Log of Mean Household Income increases graduation rates by $0.09 \%(0.01 \times 9.1425)$. Contrastingly, Hall and Leeson (2010) found a negative relationship between meanmedian income ratio and school performance. Log of Children from Single Parent Household is negatively associated with graduation rates. A $1 \%$ increase in Log of Children from Single Parent Household decreases graduation rates by 0.01\%. As shown in the previous section, high school graduation rates is found to increase in a traditional family structure where both parents are present (Palardy, 2013). Log of Instructional Salary per Pupil is associated with an increase in graduation rates as well. A 1\% increase in Log of Instructional Salary per Pupil increases the dependent variable by $0.11 \%$. Teacher Student Ratio variable is negatively related to graduation rates. While not directly related to graduation rates, teacher student ratio negatively affect dropout rates (Reardon and Galindo, 2002). Studies of the effect of this variable on graduation rates is not found.

Local Revenue as a \% of Total Revenue is associated with an increase in graduation rates. A $1 \%$ increase in this variable leads to a $0.06 \%$ increase in graduation rates. Another variable used to explain variation in graduation rates is Log of Expenditure per Pupil. Surprisingly, this variable bears a negative sign. The effect of per pupil expenditures can be hypothesized to be positive because one can expect students to get access to better resources which might subsequently lead to an increase in graduation rates with increases in per pupil spending. A $1 \%$ increase in this variable decreases graduation rates by $0.12 \%$. While the direct effects of this variable on graduation rates is not found, as mentioned in the previous section, Jackson et al. (2016) find a positive relationship between increases in per pupil spending and completed years of education. Finally, Racial Fractionalization Index, is also negatively associated with 
graduation rates. If a racially homogeneous school district, for instance, Arab City School District in Alabama with a Racial Fractionalization Index of 0.05 were to become heterogeneous, for instance, like Anniston City School District in Alabama with the index of 0.50 , we would expect the graduation rate to drop by $4.91 \%$. Explaining this result in terms of economic significance, a one standard deviation in the Racial Fractionalization Index (0.168) in a said school district decreases the graduation rate by $1.65 \%(0.168 \times-9.8361)$ or only about $15 \%(0.168 \times-9.8361 / 10.52)$ of the standard deviation of the dependent variable. Hall and Leeson (2010) also find diversity to negatively affect educational outcomes.

Since we are using a spatial hierarchical model in our study, we are also able to test the spillover effects or neighborhood effects, called indirect effects. One of the distinguishing factors between this study and previous studies is that we account for indirect effects in our analysis. The average indirect effect captures spillover effects of a change in an explanatory variable in a school district and how that affects observations of the dependent variable in neighboring school districts.

The indirect effects of a 1\% increase in Mean Household Income in a school district increases graduation rates in surrounding school districts by $0.01 \%$ and is not statistically robust. Log of Children from Single Parent Household in a school district exerts a negative effect on the graduation rates of its neighboring school districts. This variable is not statistically significant as well. An increase in Log of Instructional Salary per Pupil in a school district does not spillover to the graduation rates of surrounding school districts in a statistically significant manner. However, it exerts a positive effect. Unlike the direct effects of Teacher Student Ratio, the indirect effect is statistically significant and also positive. This means that an increase in Teacher Student Ratio in a school district positively affects the graduation rates of surrounding school districts. Local Revenue as a \% of Total Revenue increase in a school district decreases the graduation rates of surrounding school districts. This may be due to the fact that surrounding school district resources may be allocated to the referenced school district. This variable is statistically robust as well. Log of Expenditure per 
Hall, Lacombe, Pokharel Chapter 2. A Hierarchical SLX Modelling Approach 38

Pupil in a school district also decreases graduation rates in surrounding school districts and is statistically significant. It may also be the case that as state funds are distributed among school districts, the channeling of resource to one school district reduces available funds for another (surrounding) school district, all else equal. As a school district becomes more heterogeneous, graduation rates of surrounding school districts increases.

The final effect is called the total effects and is defined as the sum of direct effects and indirect effects. At this level, all variables of interest are statistically significant except for the Local Revenue as a \% of Total Revenue variable. While Log of Mean Household Income, Log of Instructional Salary per Pupil, and Teacher Student Ratio are positively related to high school graduation rates, the remaining other variables exert a negative effect on the dependent variable.

\subsubsection{Level 2 Results}

As mentioned in the "Statistical Methodology" section, advantages of using a hierarchical SLX model is its ability to include heterogeneity at the state level unlike the standard fixed effects models and also its ability to include spatially lagged independent variables at Level 2 . The inclusion of spatially lagged independent variables provides us with direct, indirect, and total effects at the state level as well. We take the DIC statistic into account at the state level analysis also and use 2 nearestneighbor spatially-weighed $\mathrm{W}$ matrix to get our estimates. Table 2.3 reports the results for this level.

As can be seen, neither (direct, indirect, or total) effects have a statistically significant influence on graduation rates at the state level. The Nation at Risk had already been published and its recommendation implemented in the three decades that followed, giving high-stakes exit exams ample time to test itself. This empirical exercise shows that state exit exams, while having a positive effect, do not have a statistically significant effect on graduation rates. The stated goal of increasing competency in core areas among high school students by conducting these high-stakes exams did not 
have any statistically significant relationship with increasing graduation rates after controlling for the embedded nature of school districts within states.

\subsection{Conclusion}

Given the longstanding history of high stakes state exit exams on high school graduation rates in the United States, it comes as no surprise that various empirical studies have found mixed results. However, these studies do not take into account the hierarchical nature of school districts and their embedded nature within state education systems. In addition, they also do not account for spatial spillovers.

Our key contribution to the literature is that, first, we employ a hierarchical model to correct for biased results from previous studies which mostly used conventional linear methods. In addition, papers with non-spatial estimates also did not account for spillover effects of the explanatory variables on graduation rates. Therefore, our second contribution to the literature is that we capture spatial spillovers in the explanatory variables to explain differences in high school graduation rates which previous non-spatial papers missed.

The school district level independent variables exhibit expected results except for the Local Revenue as a \% of Total Revenue and Log of Expenditure per Pupil. At the state level, after controlling for state-level heterogeneity, high-stakes exit exams lead to an increase in graduation rates indicating that exit exams within a state and also its neighbors leads to higher graduation rate within its school districts. However, since the results are not statistically robust, the results indicate that implementing high-stakes state exit exams does not appear to significantly improve graduation rates for school districts in states that have implemented high-stakes exams. Therefore, one important implication of this result could be that it would support the idea of replacing such policy or repealing it altogether since it has costs, both direct and indirect, yet does not produce any tangible effects in terms of graduation rates.

Moving forward, future research could look at the effect of state exit exams on 
Hall, Lacombe, Pokharel Chapter 2. A Hierarchical SLX Modelling Approach 40 other dependent variables such as the SAT scores since SAT scores have been used as a measure for student/school quality in empirical research, also in a spatial hierarchical setting. 


\section{Hall, Lacombe, Pokharel Chapter 2. A Hierarchical SLX Modelling Approach}

Table 2.1: Summary Statistics

\begin{tabular}{|c|c|c|c|c|c|}
\hline & Year & Source & Mean & $\mathrm{SD}$ & $\mathrm{N}$ \\
\hline \multicolumn{6}{|l|}{ Level 1 variables } \\
\hline High School Graduation Rates & 2013 & The Hechinger Report & 87.01 & 10.52 & 8636 \\
\hline Log of Mean Household Income & 2013 & National Center for Education Statistics(NCES) & 11.142 & 0.332 & 8636 \\
\hline Log of Children from Single Parent Household & 2013 & National Center for Education Statistics(NCES) & 5.409 & 1.484 & 8636 \\
\hline Log of Instructional Salary per Pupil & 2013 & National Center for Education Statistics(NCES) & 8.347 & 0.299 & 8636 \\
\hline Teacher Student Ratio & 2013 & National Center for Education Statistics(NCES) & 0.071 & 0.017 & 8636 \\
\hline Local Revenue as a \% of Total Revenue & 2013 & National Center for Education Statistics(NCES) & 0.436 & 0.196 & 8636 \\
\hline Log of Expenditure per Pupil & 2013 & National Center for Education Statistics(NCES) & 9.265 & 0.295 & 8636 \\
\hline Racial Fractionalization Index & 2013 & Own Calculation & 0.201 & 0.168 & 8636 \\
\hline \multicolumn{6}{|l|}{ Level 2 variables } \\
\hline State Exit Exams & 2013 & Education Counts Reseach Center & 0.46 & 0.50 & 46 \\
\hline
\end{tabular}


Hall, Lacombe, Pokharel Chapter 2. A Hierarchical SLX Modelling Approach 42

Table 2.2: Level 1 Results with State Exit Exams as Level 2 Variable with 10 NearestNeighbor W Matrix

Posterior Mean $\quad$ Lower 95\% $\quad$ Upper 95\%

Direct Effects

Log of Mean Household Income

Log of Children from Single Parent Household

Log of Instructional Salary per Pupil

Teacher Student Ratio

Local Revenue as a \% of Total Revenue

Log of Expenditure per Pupil

Racial Fractionalization Index

$\begin{array}{rrr}9.1425^{*} & 8.3242 & 9.9714 \\ -1.5064^{*} & -1.687 & -1.3270 \\ 10.5953^{*} & 8.3903 & 12.8064 \\ -2.1503 & -21.2034 & 16.9158 \\ 5.7662^{*} & 4.3493 & 7.1720 \\ -12.1008^{*} & -14.3261 & -9.8889 \\ -9.8361^{*} & -11.5274 & -8.1611 \\ & & \\ & & \\ 1.1813 & -0.5611 & 2.8925 \\ -0.0898 & -0.4787 & 0.2987 \\ 4.4278 & -0.4308 & 9.3015 \\ 41.4082^{*} & 5.7646 & 76.7633 \\ -6.9605^{*} & -9.6596 & -4.2404 \\ -5.7156^{*} & -10.2933 & -1.1245 \\ 1.3371 & -1.7995 & 4.4791\end{array}$

Indirect Effects

Log of Mean Household Income

Log of Children from Single Parent Household

Log of Instructional Salary per Pupil

Teacher Student Ratio

Local Revenue as a \% of Total Revenue

Log of Expenditure per Pupil

Racial Fractionalization Index

1.3371

$-1.7995$

4.4791

Total Effects

Log of Mean Household Income

$10.3238^{*} \quad 8.6099 \quad 11.9962$

Log of Children from Single Parent Household

$-1.5963 * \quad-1.9826$

$-1.2105$

Log of Instructional Salary per Pupil

$15.0231^{*} \quad 9.9813$

20.0837

Teacher Student Ratio

$39.2579^{*}$

2.1561

76.5986

Local Revenue as a \% of Total Revenue

$-1.1942 \quad-3.8648$

1.4693

Log of Expenditure per Pupil

$-17.8164^{*} \quad-22.5809$

$-13.0966$

Racial Fractionalization Index

$-8.499 * \quad-11.3734$

$-5.6083$

Variance Posterior Mean

Level 1 Error Variance: $\sigma^{2}$

7.9333

Level 2 Error Variance: $\tau^{2}$

4.4596

DIC

2382850.71

Note: $\mathrm{N}=8636 .{ }^{*}$ denotes variables with a $95 \%$ confidence interval without a 0 . 
Table 2.3: State Exit Exam (Level 2) Results with 2 nearest-neighbor W matrix

\begin{tabular}{lrrr}
\hline & Posterior Mean & Lower 95\% & Upper 95\% \\
\hline Constant & 84.8674 & 82.5629 & 87.137 \\
Direct Effect & 0.7523 & -1.9255 & 3.4732 \\
Indirect Effect & 0.8676 & -2.8889 & 4.6017 \\
Total Effect & 1.6199 & -2.7314 & 5.902 \\
\hline
\end{tabular}

Note: $\mathrm{N}=46 .{ }^{*}$ denotes variables with a $95 \%$ confidence interval without a 0 . 


\section{Chapter 3}

\section{Federal Regulations in the United States Wine Value Chain Over Time}

\subsection{Introduction}

Published by the Mercatus Center, RegData is a numerical quantification of federal regulatory restrictions across all North American Industry Classification System (NAICS) industries. According to RegData, federal regulatory restrictions in the US have been steadily increasing over time. It increased from approximately 800,000 in 1997 to approximately over 1 million in 2012 across all NAICS industries (Al-Ubaydli and McLaughlin, 2017) ${ }^{1}$.

The negative economic consequences of such restrictions are well documented in the literature. For instance, Dawson and Seater (2013) and McLaughlin and Williams (2017) show a negative relationship between increases in federal restrictions and economic growth. Davies (2014) show lower production-efficiency measures in more

\footnotetext{
${ }^{1}$ One has to take notice while interpreting this regulatory number. It does not represent the number of laws or regulations in the traditional sense. According to RegData, it represents the summation of number of restrictive regulatory words such as "shall", "must", "may not", "prohibited", and "required" that appeared in the Code of Federal Regulations (CFR) pertaining to each NAICS industry.
} 
regulated industries. For instance, the author finds a $64 \%$ growth in output per person in the least regulated industries. Bailey and Thomas (2015) find fewer new firm births and slower employment growth in more regulated industries. Chambers and Collins (2016) find federal regulations to affect poor households unevenly by regressively increasing consumer prices.

These studies report the effect of federal restrictions at the more macro level or its more specific narrow impacts, for example, on rate of new firm births. However, not much research has been done on its impact on specific value chains. Particularly its effect on wine value chains has not been studied. Malone and Chambers (2017) is the only other research that quantifies the number of federal regulatory restrictions on a specific value chain. Malone and Chambers (2017) find that there are over 20,000 federal restrictions on the beer value chain in 2012. While their paper is helpful in better understanding changes to the beer value chain over time, without another product to compare it to it is difficult to place their findings in a comparative context. The purpose of this paper is to calculate the number of federal restrictions imposed on each wine value chain over time. Therefore, using RegData, this paper reports the number of total federal regulatory restrictions on wine production and distribution channels in the United States from 1997 to 2012.

For the purposes of this study, wine value chain is classified as "Wineries" (NAICS: 31213), "Wine and Distilled Alcoholic Beverage Merchant Wholesalers" (NAICS: 42482), and "Beer, Wine and Liquor Stores" (NAICS:44531). Wineries account for the manufacturing/production aspect of the value chain. As the name suggests, Wine and Distilled Alcoholic Beverage Merchant Wholesalers account for the wholesale distribution aspect of the value chain. Finally, Beer, Wine and Liquor Stores account for the retail side of the value chain. This classification is intended to capture the three-tier system that US states adopted for alcohol production and distribution after the 21st amendment.

The study of wine value chains in addition to beer value chains adds to the literature primarily by distinguishing that inputs in both industries face different number 
of federal regulations and allowing for comparison. Because the primary input that goes into making wine, i.e. grapes, is different than the primary inputs that goes into making beer, for instance, barley and hops, the wine industry faces different numbers of federal regulations than the beer industry.

Additionally, this study also adds to the literature by identifying that the setup of both industries are distinct from one another. While the US wine industry is concentrated in California and is dominant in terms of production, the beer industry is not as concentrated. For example, in June 2017, 4,202 out of 9,091 total US wineries were situated in California alone and produced $282,000,000^{2}$ net cases of wine. Washington housed 747 out of 9,091 total US wineries and produced 15,000,000 net cases while Oregon housed 713 wineries and produced 4,200,000 cases of wine (Wine and Vines, 2017). Contrastingly, the beer industry is not as concentrated. The top three beer producers while producing approximately similar units of beer are located in different parts of the country. In 2012, Pennsylvania produced about 3,000,000 barrels of beer. California produced a little over 2,500,000 barrels of beer whereas Massachusetts produced a little less than 2,500,000 barrels of beer (Elzinga et al., 2015). Therefore, generalizing beer statistics to the wine industry though might be argued to be qualitatively similar, is not quantitatively accurate.

The number of small wineries are growing in the US from 7,763 in 2014 to 9,091 in 2017 (Wine and Vines, 2017). ${ }^{3}$ At the same time, only 5 firms control approximately $65 \%$ of the wine market share in the US (Howard et al., 2017). Therefore, one can expect that larger wineries would lean towards regulatory constraints that act as a barrier to entry to keep away their competition, i.e., smaller wineries (Gohmann, 2016), at least within a country.

Internationally, US wine exports face restrictive export trade barriers. For example, the import tariff in wine exporting countries is comparatively very high as compared to the US, which has an import tariff of $1.4 \%$. Contrastingly, it is ap-

\footnotetext{
${ }^{2}$ One case contains $9 \mathrm{~L}$ wine.

${ }^{3}$ According to Wine and Vines (2017), small wineries are wineries that produce less than 49,000 cases containing $9 \mathrm{~L}$ wine bottles annually.
} 
proximately $32 \%$ within the EU and $22.5 \%$ within Japan (The Wine Institute, 2017). Therefore, one can expect that with not being able to export internationally as much as wineries would desire, big wineries would seek to protect their market share by at least restricting the growth of small wineries within the US. Additionally, since small wineries produced over 97 million cases and large brewers produced over 162 million cases of wine on the upper bound in January 2017 (Wine and Vines, 2017), it lends credence to the theory of regulatory capture in some level by big wineries. These might be few reasons for the overwhelming amount of federal restrictions on wine value chains.

I find that federal restrictions imposed on wineries were approximately 55,000 in 2012. In the same year, federal regulatory restrictions imposed on the wine wholesalers was approximately 23,000 , and an estimated 20,000 on retail wine stores. ${ }^{4}$

\subsection{Data}

In order to measure industry-specific regulation over time, I use a recently developed data source: RegData. Complied by the Mercatus Center, RegData (Al-Ubaydli and McLaughlin (2017)) measures industry-specific regulation over time. RegData is created as such: the authors scan the Code of Federal Regulations(CFR) - a federal publication published annually containing all regulations imposed by the federal government - each year and apply the restrictions in the CFR to each NAICS industry. They do so by searching for words that indicate binding constraints such as "shall", "must", "may not", "prohibited", and "required" in each title, chapter, subchapter, part, subpart, section, and paragraph of the CFR. Simultaneously, since the divisions of the CFR do not perfectly match with the NAICS industries, they create a set of words called "search strings" to represent each NAICS industry. They then apply those search strings to each division of the $C F R$ to see its industry relevance. The

\footnotetext{
${ }^{4}$ As mentioned before, these number measure the number of restrictive regulatory words pertaining to Wineries (NAICS: 31213), Wine Wholesalers (NAICS: 42482), and Wine Retail Stores (NAICS: 44531).
} 
two sets of data are then combined to create an industry-specific regulation index to indicate what Al-Ubaydli and McLaughlin (2017) label as "industry regulation index".

To put this in perspective, Title 27, Chapter 1 , Subchapter D of the $C F R$ states regulations pertaining to wine production establishment. It states that:

"Each person desiring to conduct operations in wine production, as specified in 24.101(b), (other than the production of wine free of tax as provided in 24.75 through 24.77 ) shall, prior to commencing operations, establish wine premises, make application as provided in 24.105, file any required bond, and receive permission to operate wine premises as provided in this part. After approval, the wine premises will be designated a bonded winery, bonded wine cellar or taxpaid wine bottling house. As provided in 24.107, the designated bonded winery will be used if production operations are to be conducted. In addition, wine premises may be used, in accordance with the provisions of this part, for the conduct of certain other operations."

In this example, this text is counted as one regulation as it has a one time occurrence of the word "shall."

I use RegData as opposed to previous measures of regulation mainly because this measure is a detailed quantification of regulations which previous measures lacked to capture. Previous measures of regulations looked at state-statutes' file size (Mulligan and Shleifer, 2005) or page counts (De Rugy and Davies, 2009; Coffey et al., 2012; Dawson and Seater, 2013). De Rugy and Davies (2009), for example, use page counts from the Federal Register as their measure of federal regulations. Federal Register is daily publication and is a collection of all federal regulations ever written. The disadvantage of using page counts as a measure of capturing regulations is that not all pages have equal regulation as some pages might have significant regulatory impact while others might not. In addition, not all pages contain regulatory text, which severely overstates the impact of regulations. Additionally, the Federal Register does not quantify regulations targeting specific industries. RegData, on the other hand, uses binding constraints and targets specific industries that studies with page count 
or other measures did not.

The advantage of using the $C F R$ instead of the Federal Register is that the $C F R$ contains text without the repetition of added regulations. While the Federal Register contains all regulations ever written or added to current regulations, the $C F R$ only contains text after all regulations that have been repealed are removed.

RegData, however, contains regulatory data only for the 1-to 4-digit NAICS subsector. Since "Wineries" (NAICS: 31213) is a 5-digit NAICS subsector, following the methodology of Malone and Chambers (2017), direct federal regulations related to the process of wine manufacturing is estimated by subtracting federal regulations associated with the 4-digit "Tobacco Manufacturing" (NAICS: 3122) sector from the 3-digit "Beverage and Tobacco Product Manufacturing" (NAICS: 312) sector. The residual is "Beverage Manufacturing" (NAICS: 3121) which consists of "Soft Drink and Ice Manufacturing", "Breweries", "Wineries", and "Distilleries." As mentioned in the introduction, "Wineries" represents the first component of the wine value chain in this paper. The second component of the wine value chain is termed "Wholesale Distribution" and represents "Wine and Distilled Alcoholic Beverage Merchant Wholesalers" (NAICS: 42482). Since regulations for the 5-digit NAICS subsector is not available in RegData, federal regulations for this value chain is captured by the 2digit "Wholesale Trade" (NAICS: 42) sector. The third component of the wine value chain, "Beer, Wine and Liquor Stores" (NAICS:44531) is captured by the broader "Food and Beverage Stores" (NAICS: 445), again, as data for the this 5-digit subsector is not available. "Beer, Wine and Liquor Stores" (NAICS:44531) is referred as "Wine Retail Sales" in the subsequent part of this paper.

While direct federal regulations measure a part of federal restrictions imposed on each value chain, they do not provide a comprehensive measure. Since inputs such as grapes and agricultural labor are required in each wine value chain, capturing restrictions on such inputs is also necessary. Therefore, following Malone and Chambers (2017), federal restrictions on inputs required at each value chain is estimated. To estimate the input restrictions on each value chain, RegData is combined with the 
input-output (I-O) tables from the Bureau of Economic Analysis (BEA) following Chambers and Collins (2016).

The methodology for finding input regulations for each year from 1997 to 2012 for Wineries (NAICS: 31213), Wholesale Distribution (NAICS: 42), and Wine Retail Sales (NAICS: 445) is mentioned below. The steps are as follows:

1. The commodity-by-industry direct requirements table (after redefinitions) was downloaded from the BEA website for the year 2007. The website is: http:// www.bea.gov/industry/xls/io-annual/CcI \_DR\_2007\_detail.xlsx. This table contains three worksheets.

(i) The first worksheet is a ReadMe file.

(ii) The second worksheet is a concordance table that relates each BEA code to each related NAICS code.

(iii) The third worksheet contains data on the input requirements (measured in dollars) of each commodity/industry to produce a dollar's worth of output for a particular industry. Therefore, for each column in the table (in our case, Wineries (NAICS: 312130), Wholesale Distribution (NAICS: 420000), and Wine Retail Sales (NAICS: 445000)), the values are summed across all rows related to that column to get a composite measure of input required to produce a dollar's worth of output for that particular column. The numbers sum to 1 as the BEA also adds gross operating surplus, taxes on production and imports, and compensation to employees, among others, in addition to inputs.

2. The BEA concordance table (the second worksheet from the downloaded table) was then "matched" to related NAICS industry. If there was a one-tomany mapping while matching BEA code to NAICS code, the results were summed over the NAICS code. For example, BEA code 1111A0 (Oilseed Farming) matches to two NAICS code 11111 and 11112 at the same time. However, 
due to the lack of 5-digit NAICS code data in RegData, the 1111A0 BEA industry was matched to NAICS code $\{1111,1111\}$. This NAICS set is then translated to NAICS: 1111 as NAICS: 1111 is an aggregation of the 5-digit NAICS industries. A column with the newly matched "BEA-NAICS" industries is then created in this process whose rows contain the newly matched BEA-NAICS industry codes.

3. The next step involved matching federal regulatory restrictions for the newly matched BEA-NAICS industry with RegData. "Industry Regulation Index" measure in RegData was used.

4. In the next step, the newly created rows containing the industry regulation index for each BEA-NAICS industry is then multiplied with its corresponding input value to create an input-regulation measure for each BEA-NAICS industry.

5. In the final step, values in step 4 were summed across all rows to get an aggregate input-regulation measure for each of the above mentioned NAICS industries, namely, Wineries (NAICS: 312130), Wholesale Distribution (NAICS: 420000), and Wine Retail Sales (NAICS: 445000).

Finally, direct regulations are combined with input regulations to get the complete measure of total federal regulations for each value chain.

\subsection{Empirical Results}

Tables 3.1, 3.2, and 3.3 report the direct, input, and total federal regulations imposed on each wine value chain from 1997-2012. "Direct", "Input", and "Total" in the tables correspond to Direct Federal Regulations, Input Federal Regulations, and Total Federal Regulations, respectively. For each year and specific value chain, Direct Federal Regulations represent the number of federal restrictions across all divisions in the $C F R$ pertaining to that specific value chain. Inputs such as grapes and agricultural labor are required to produce wine. Therefore, Input Federal Regulations represent 
the input regulations pertaining to that value chain. Total Federal Regulations is the summation of direct and input regulations.

Table 3.1 shows that Wineries was subjected to approximately 40,000 direct federal regulations in 1997. This number steadily decreased to approximately 23,000 in 2003 and increased to about 30,000 in 2012. While direct regulation measure is an estimate derived from differencing the 4-digit "Tobacco Manufacturing" (NAICS: 3122) sector from the 3-digit "Beverage and Tobacco Product Manufacturing" (NAICS: 312) sector, input regulation measure for wineries is specific to the industry. Inputs used in wineries were subjected to about 23,000 federal restrictions in 1997 . It decreased to approximately 20,000 in 2000 . It then increased to an estimated 24,000 in 2012. Wineries were subjected to approximately 63,000 federal restrictions in 1997. This number decreased to about 44,400 in 2003 and while not as high as in 1997, it increased to approximately 55,000 in 2012.

While not as much as Wineries, Wholesale Distribution also faced a substantial amount of direct, input, and total federal restrictions. Table 3.2 reports that Wholesale Distribution faced about 6,800 restrictions in 1997 . It decreased in the early 2000s and increased to around 6,400 in 2012. Input regulations were more than double of direct regulations for Wholesale Distribution. In 1997, Wholesale Distribution faced about 18,600 regulations. In 2012, this number decreased to about 17,300. Total regulations also decreased from approximately 25,500 in 1997 to about 24,000 in 2012.

Wine Retail Sales direct, input, and total regulations are reported in Table 3.3. This value chain faced the least amount of regulations among all value chains. It faced about 469 direct federal restrictions in 1997, about 1,300 direct federal restrictions in 2002, and approximately 1,000 direct restrictions in 2012. However, as compared to direct restrictions, it faced a large number of input restrictions. There were about 19,000 input restrictions on Wine Retail Sales in 1997. This number decreased to about 17,000 in 2000 and it increased to a high of approximately 19,600 in 2012. Similarly, total restrictions increased from 19,420 in 1997 to 20,619 in 2012. 
Finally, Table 3.4 reports the Comprehensive measure of total federal restrictions across all value chains from 1997 to 2012. For each year in the sample, total federal restrictions for Wineries, Wholesale Distribution, and Wine Retail Sales are summed to derive the comprehensive measure. The comprehensive measure of regulations show that for all wine value chains, federal restrictions declined steeply from approximately 107,000 in 1997 to estimated 85,000 in 2001. It then increased steadily to about 100,000 in 2012.

For comparison purposes, Direct, Input, and Total restrictions for each value chain are visually represented in Figure 3.1, 3.2, and 3.3. Figure 3.1 shows total direct regulations imposed on Wineries, Wholesale Distribution, and Wine Retail Sales. The table shows that direct federal restrictions on Wineries is more than five times than that of Wholesale Distribution and Wine Retail Sales. Whole Distribution and Wine Retail Sales direct regulations was steady over time. Low numbers of federal restrictions on wholesale and retail distribution of wine are as expected as historically states rather than the federal government intervened in these value chains (Malone and Chambers, 2017).

As mentioned before, inputs such as grapes and agricultural labor are required to produce wine. Figure 3.2 reports federal restrictions imposed on inputs on Wineries, Wholesale Distribution, and Wine Retail Sales. Federal input regulations remained steady for all three value chains. Input regulations on Wineries is still highest among the value chains. Wine Retail Sales faced more input regulations than Wholesale Distribution in the sample.

Figure 3.3 reports total federal restrictions for each value chain from 1997 to 2012. Each line in the graph represents a summation of total direct restrictions and total input restrictions on each value chain over time. Total restrictions faced by Wineries is more than two times the total restrictions faced by wholesale wine sellers and retail wine sellers. Total federal restrictions remained stable throughout the years for both Wholesale Distribution and Wine Retail Sales.

Finally, it should also be noted that the Comprehensive measure in Table 3.4 is 
different than Malone and Chambers (2017) because of the difference in input regulations for Wineries. However, due to lack of data, regulation values for wholesale and retail distribution channels are the same in both studies for all years. For instance, in 1997, there were $6,825.41,18,625.89$, and 25,451.29 direct, input, and total restrictions in Wholesale Distribution in both this study and Malone and Chambers (2017). Wine Retail Sales direct, input, and total regulations were also same in both the studies. However, while direct regulations were same for Wineries, there were 22,993.64 input regulations in 1997 in this study and 16,788.47 in Malone and Chambers (2017).

\subsection{Limitations}

This study faces a number of limitations. Most limitations are present primarily due to lack of availability of data. First, this study only estimates federal restrictions associated with the Code of Federal Regulations and does not account for state and local regulations imposed on each of the value chains studied. While studies such as Mulligan and Shleifer (2005), Campbell et al. (2010), and Calcagno and Sobel (2014) have measured state regulations, they are not comparable to RegData. RegData quantifies regulatory restrictions pertaining to each NAICS industry while current measures use regulatory measures that are not classified according to NAICS. For instance, Campbell et al. (2010), and Calcagno and Sobel (2014) use state direct expenditures on regulatory practices as a proxy for regulatory restrictions and is, therefore, not comparable. Since most states have a three tier distribution system and they are regulated at each of the three tiers (value chains) (Beliveau and Rouse, 2010), addition of those regulations would provide with a much richer set of results. However, due to the lack of availability of data, this study uses federal restrictions only.

Second, RegData contains federal regulatory restrictions data for 2, 3 and $4-$ digit NAICS industries. Therefore, instead of using a direct regulation measure for "Wineries" (NAICS: 312130), a 5-digit NAICS industry, this study uses the regula- 
tory measure for "Beverage Manufacturing" (NAICS: 3121) industry. NAICS: 3121 contains "Soft Drink and Ice Manufacturing", "Breweries", "Wineries", and "Distilleries". Again, much better set of results can be calculated once data for 5-digit NAICS industries become available.

Third, this study does not account for federal regulations in on-premise sales. Onpremise sales like wine sales in restaurants might face additional federal restrictions. Once more, when data for such sales become available, adding it to the three-tier system would provide with precise number of regulations imposed on these value chains.

Fourth, due to lack of availability of granulated data for the "Wine and Distilled Alcoholic Beverage Merchant Wholesalers" (NAICS: 42482) industry in the BEA input-output table, the 2-digit "Wholesale Trade" (NAICS: 42) industry was used as a proxy in order to calculate federal restrictions on the "Wholesale Distribution" chain. Similarly, regulatory data for the broader "Food and Beverage Stores" (NAICS: 445) was used instead of the granulated "Beer, Wine, and Liquor Stores" (NAICS: 44531) industry to proxy for "Wine Retail Sales".

Finally, at this point, this study is not able to answer the reasons for an increase or decrease of federal regulations in wine value chains over time. Making accurate judgments regarding the source of changes should be possible once more granular data becomes available.

Even though this study has a number of limitations and reports an upper bound of federal restrictions imposed on wine value chains, it also shows that there is a number of federal regulations imposed on the wine value chain overall and that these regulations are persistent. While the comprehensive measure of federal regulations has decreased from over a 100,000 federal regulations in 1997 to just under 100,000 in 2012, it still seems quite large. Future research could expand upon this study once comparable data on state and local regulations become available or data on the more granulated level become available. Future studies could also identify the causes of the increase or decrease of regulation on each wine value chain and also the consequences 
of such changes.

\subsection{Conclusion}

This study calculates the number of federal regulatory restrictions on each wine value chain, namely, restrictions on Wineries, Wholesale Distribution, and Wine Retail Sales. It does so by combining federal regulatory restriction data from RegData with the direct requirements input-output table from the Bureau of Economic Analysis and reports that the number of federal regulations on wine value chain is decreasing. However, the number of federal restrictions is still overwhelming at approximately 100,000 in 2012 . This large number might be in place because the federal government is trying to increase their oversight on a consumption good, i.e. wine, and also because the big wineries are trying to impede the growth of smaller wineries (Malone and Chambers, 2017).

The current literature on agribusiness value chains has calculated the number of federal regulatory restrictions on the beer value chain. The primary contribution of this study to this current literature is that it calculates the number of federal restrictions on the wine value chain. Since both industries are different in terms of the inputs they use and in terms of geographic concentration which might affect their production and distribution channels, identification of federal restrictions on each value chain for these separate industries is informative. 
Table 3.1: Direct, Indirect, and Total Federal Regulation Imposed on Wineries

\begin{tabular}{crrr}
\hline & \multicolumn{3}{c}{ Wineries $^{\mathbf{a}}$} \\
\cline { 2 - 4 } Year & Direct & Input $^{\mathbf{b}}$ & Total \\
\hline 1997 & $39,727.61$ & $22,993.64$ & $62,721.25$ \\
1998 & $38,356.40$ & $20,240.49$ & $58,596.89$ \\
1999 & $29,459.41$ & $19,969.14$ & $49,428.55$ \\
2000 & $26,809.29$ & $19,535.14$ & $46,344.43$ \\
2001 & $24,861.82$ & $20,066.27$ & $44,928.09$ \\
2002 & $24,944.79$ & $20,724.71$ & $45,669.50$ \\
2003 & $23,270.40$ & $21,140.50$ & $44,410.90$ \\
2004 & $27,467.65$ & $22,061.61$ & $49,529.26$ \\
2005 & $26,317.78$ & $21,581.07$ & $47,898.85$ \\
2006 & $27,597.68$ & $21,855.80$ & $49,453.49$ \\
2007 & $28,000.17$ & $22,010.04$ & $50,010.22$ \\
2008 & $27,916.85$ & $22,712.24$ & $50,629.09$ \\
2009 & $28,526.91$ & $22,888.64$ & $51,415.54$ \\
2010 & $31,822.08$ & $23,458.33$ & $55,280.41$ \\
2011 & $31,305.31$ & $23,635.01$ & $54,940.32$ \\
2012 & $30,812.15$ & $24,405.97$ & $55,218.12$ \\
\hline
\end{tabular}

Note: "Direct", "Indirect", "Total" in the table correspond to Direct Federal Regulations, Indirect Federal Regulations, and Total Federal Regulations.

${ }^{a}$ Wineries (NAICS: 31213) direct regulations is equal to the difference between "Beverage and Tobacco Product Manufacturing" (NAICS: 312) and "Tobacco Manufacturing" (NAICS: 3122). The residual is equal to "Beverage Manufacturing" (NAICS: 3121), which includes "Soft Drink and Ice Manufacturing" (NAICS: 31211), "Breweries" (NAICS: 31212), "Wineries" (NAICS: 31213), and "Distilleries" (NAICS: 31214).

b Wineries (NAICS: 31213) input regulations are specific to the industry and is derived using Chambers and Collins (2016)' methodology. 
Table 3.2: Direct, Indirect, and Total Federal Regulation Imposed on Wholesale Distribution

\begin{tabular}{ccrr}
\hline & \multicolumn{3}{c}{ Wholesale Distribution } \\
\cline { 2 - 4 } Year & Direct & Input & Total \\
\hline 1997 & $6,825.41$ & $18,625.89$ & $25,451.29$ \\
1998 & $5,984.36$ & $16,321.78$ & $22,306.13$ \\
1999 & $7,191.22$ & $15,804.10$ & $22,995.32$ \\
2000 & $6,148.99$ & $15,504.99$ & $21,653.98$ \\
2001 & $5,992.14$ & $15,698.18$ & $21,690.32$ \\
2002 & $6,038.73$ & $15,712.27$ & $21,751.00$ \\
2003 & $5,769.98$ & $15,499.26$ & $21,269.24$ \\
2004 & $5,988.41$ & $15,961.81$ & $21,950.22$ \\
2005 & $6,010.36$ & $15,759.78$ & $21,770.14$ \\
2006 & $6,432.74$ & $15,754.71$ & $22,187.45$ \\
2007 & $6,848.47$ & $15,825.96$ & $22,674.43$ \\
2008 & $6,944.40$ & $16,029.97$ & $22,974.37$ \\
2009 & $6,941.11$ & $16,129.57$ & $23,070.68$ \\
2010 & $6,378.70$ & $16,531.02$ & $22,909.72$ \\
2011 & $6,481.43$ & $16,740.18$ & $23,221.62$ \\
2012 & $6,422.83$ & $17,364.65$ & $23,787.48$ \\
\hline
\end{tabular}

Note: "Direct", "Indirect", "Total" in the table correspond to Direct Federal Regulations, Indirect Federal Regulations, and Total Federal Regulations.

a 2-digit "Wholesale Trade" sector is a proxy for "Wine and Distilled Alcoholic Beverage Merchant Wholesalers" (NAICS: 42482). 
Table 3.3: Direct, Indirect, and Total Federal Regulation Imposed on Wine Retail Sales

\begin{tabular}{lrrr}
\hline & \multicolumn{3}{c}{ Wine Retail Sales } \\
\cline { 2 - 4 } Year & Direct & Input & Total \\
\hline 1997 & 469.23 & $18,950.85$ & $19,420.08$ \\
1998 & 921.50 & $17,216.01$ & $18,137.51$ \\
1999 & 916.69 & $17,147.10$ & $18,063.80$ \\
2000 & 932.46 & $17,145.08$ & $18,077.54$ \\
2001 & 960.54 & $17,509.67$ & $18,470.21$ \\
2002 & $1,351.20$ & $17,742.20$ & $19,093.40$ \\
2003 & $1,259.17$ & $17,185.57$ & $18,444.74$ \\
2004 & $1,277.90$ & $17,614.28$ & $18,892.18$ \\
2005 & $1,269.40$ & $17,569.18$ & $18,838.57$ \\
2006 & $1,073.83$ & $17,718.50$ & $18,792.33$ \\
2007 & $1,188.39$ & $17,716.66$ & $18,905.06$ \\
2008 & $1,166.13$ & $18,033.87$ & $19,200.00$ \\
2009 & $1,149.44$ & $17,568.72$ & $18,718.16$ \\
2010 & $1,145.59$ & $18,455.96$ & $19,601.55$ \\
2011 & 983.89 & $18,972.43$ & $19,956.32$ \\
2012 & 983.88 & $19,635.07$ & $20,618.96$ \\
\hline
\end{tabular}

Note: "Direct", "Indirect", "Total" in the table correspond to Direct Federal Regulations, Indirect Federal Regulations, and Total Federal Regulations.

a 3-digit "Food and Beverage Stores" (NAICS: 445) is a proxy for "Beer, Wine, and Liquor Stores" (NAICS: 44531). 
Table 3.4: Comprehensive Measure of Federal Restrictions on each Value Chain

\begin{tabular}{lrrrr}
\hline Year & $\begin{array}{c}\text { Total } \\
\text { Wineries }\end{array}$ & $\begin{array}{c}\text { Total } \\
\text { Wholesale }\end{array}$ & $\begin{array}{r}\text { Total } \\
\text { Wine Retail }\end{array}$ & Comprehensive \\
\hline 1997 & $62,721.25$ & $25,451.29$ & $19,420.08$ & $107,592.63$ \\
1998 & $58,596.89$ & $22,306.13$ & $18,137.51$ & $99,040.52$ \\
1999 & $49,428.55$ & $22,995.32$ & $18,063.80$ & $90,487.67$ \\
2000 & $46,344.43$ & $21,653.98$ & $18,077.54$ & $86,075.95$ \\
2001 & $44,928.09$ & $21,690.32$ & $18,470.21$ & $85,088.62$ \\
2002 & $45,669.50$ & $21,751.00$ & $19,093.40$ & $86,513.90$ \\
2003 & $44,410.90$ & $21,269.24$ & $18,444.74$ & $84,124.88$ \\
2004 & $49,529.26$ & $21,950.22$ & $18,892.18$ & $90,371.67$ \\
2005 & $47,898.85$ & $21,770.14$ & $18,838.57$ & $88,507.57$ \\
2006 & $49,453.49$ & $22,187.45$ & $18,792.33$ & $90,433.27$ \\
2007 & $50,010.22$ & $22,674.43$ & $18,905.06$ & $91,589.71$ \\
2008 & $50,629.09$ & $22,974.37$ & $19,200.00$ & $92,803.46$ \\
2009 & $51,415.54$ & $23,070.68$ & $18,718.16$ & $93,204.37$ \\
2010 & $55,280.41$ & $22,909.72$ & $19,601.55$ & $97,791.68$ \\
2011 & $54,940.32$ & $23,221.62$ & $19,956.32$ & $98,118.26$ \\
2012 & $55,218.12$ & $23,787.48$ & $20,618.96$ & $99,624.56$ \\
\hline
\end{tabular}

Note: "Total Wineries", "Total Wholesale", "Total Wine Retail" in the table correspond to Total restrictions in Wineries, Total restrictions in Wholesale Distribution, and Total restrictions in Wine Retail Sales. "Comprehensive" corresponds to the summation of total federal regulations throughout all value chains in the study for each year. 
Figure 3.1: Total Direct Federal Restrictions on Each Wine Value Chain Over Time (1997-2012)

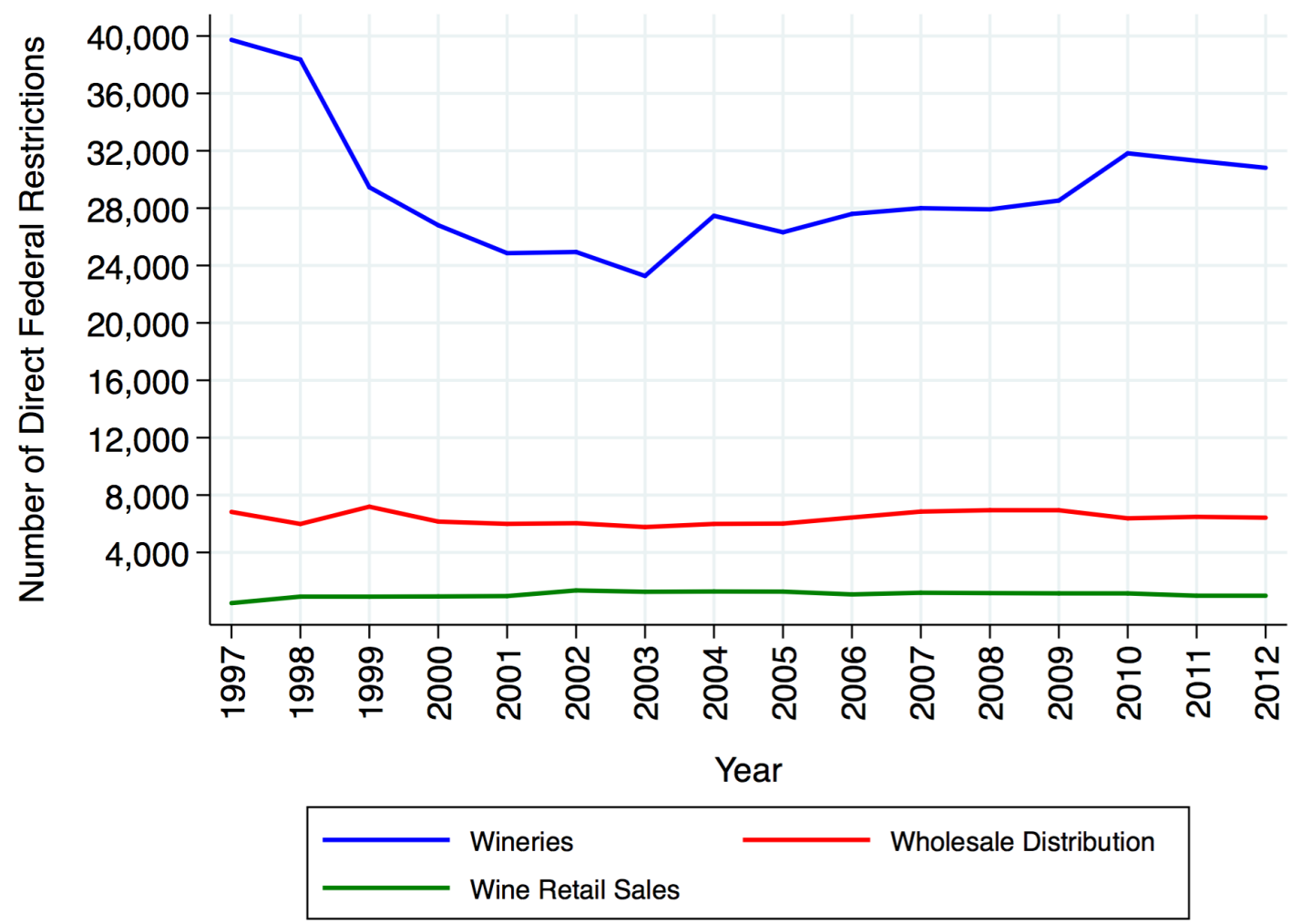


Figure 3.2: Total Input Federal Restrictions on Each Wine Value Chain Over Time (1997-2012)

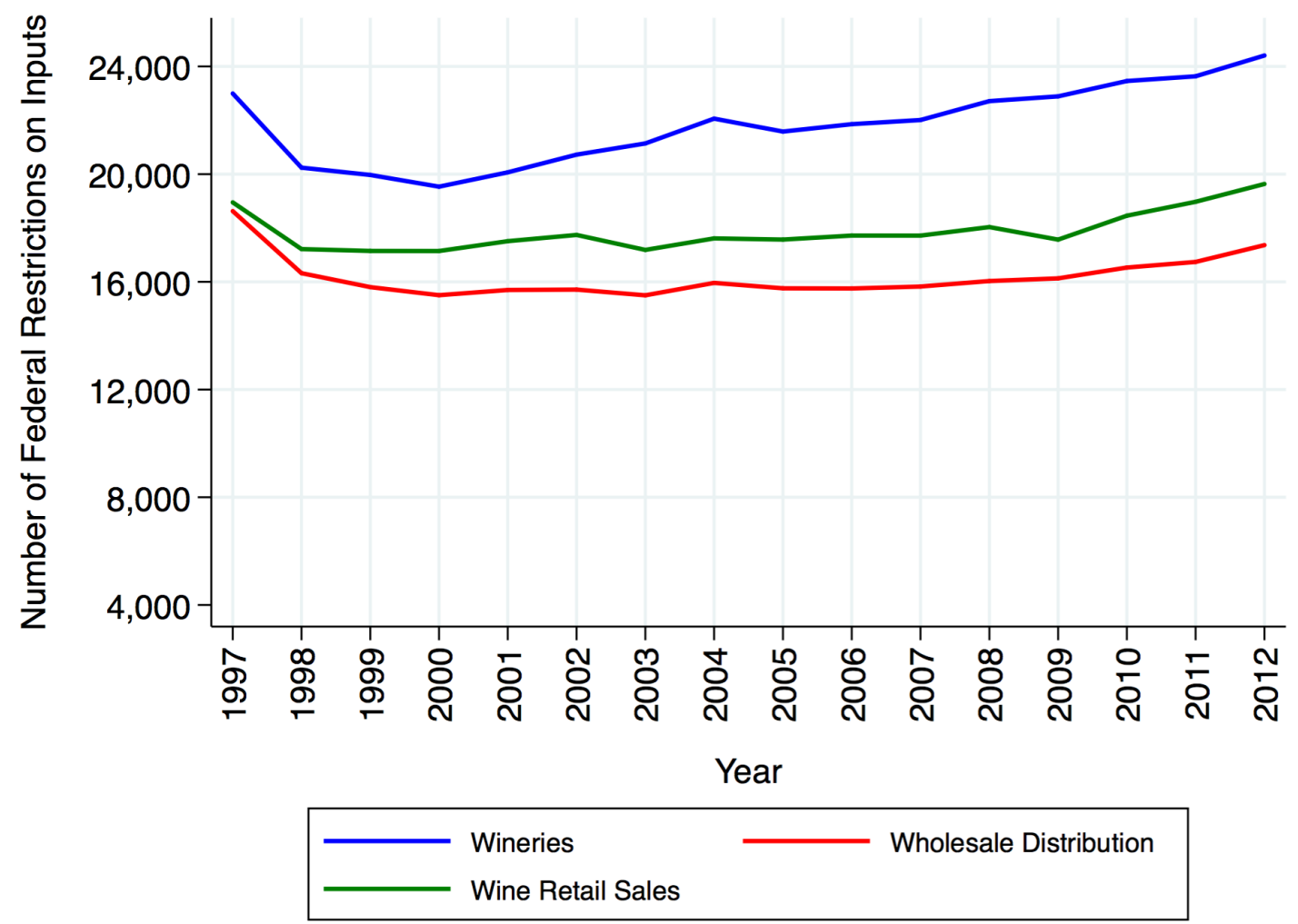


Figure 3.3: Total (Direct + Indirect) Federal Restrictions on Each Wine Value Chain Over Time (1997-2012)

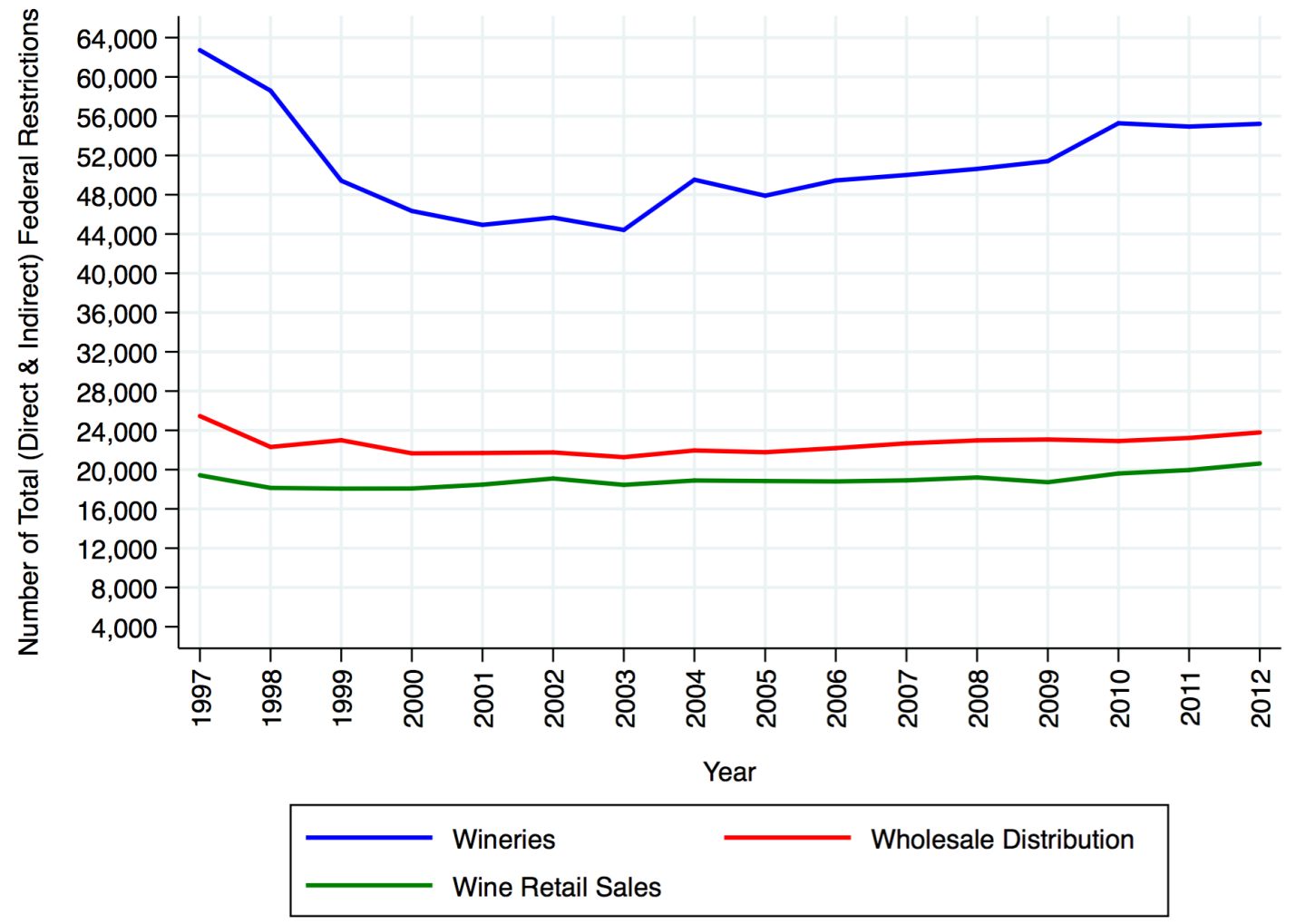


References

\section{References}

Adewale, A. J., Hayduk, L., Estabrooks, C. A., Cummings, G. G., Midodzi, W. K., and Derksen, L. (2007). Understanding hierarchical linear models: Applications in nursing research. Nursing Research, 56(4):S40-S46.

AERA (2017). Position statement on high-stakes testing. http://http: //www .aera.net/About-AERA/AERA-Rules-Policies/Association-Policies/ Position-Statement-on-High-Stakes-Testing.

Al-Ubaydli, O. and McLaughlin, P. A. (2017). Regdata: A numerical database on industry-specific regulations for all US industries and federal regulations, 19972012. Regulation and Governance, 11(1):109-123.

Anderson, K. and Nelgen, S. (2011). Global Wine Markets, 1961 to 2009: A Statistical Compendium. University of Adelaide Press.

Bailey, J. and Thomas, D. (2015). Regulating away competition. Mercatus Working Paper, George Mason University, Arlington, VA.

Baker, O. and Lang, K. (2013). The effect of high school exit exams on graduation, employment, wages and incarceration. Working Paper 19182, National Bureau of Economic Research.

Beardsley, A. and Berliner, D. C. (2002). High-stakes testing, uncertainty, and student learning. Education Policy Analysis Archives, 10(18).

Becker, G. S. (1983). A theory of competition among pressure groups for political influence. The Quarterly Journal of Economics, 98(3):371-400.

Beliveau, B. C. and Rouse, M. E. (2010). Prohibition and repeal: A short history of the wine industry's regulation in the United States. Journal of Wine Economics, $5(01): 53-68$. 
Berry, W. D., Fording, R. C., Ringquist, E. J., Hanson, R. L., and Klarner, C. E. (2010). Measuring citizen and government ideology in the US states: A re-appraisal. State Politics 6 Policy Quarterly, 10(2):117-135.

Besley, T. J. and Rosen, H. S. (1998). Vertical externalities in tax setting: Evidence from gasoline and cigarettes. Journal of Public Economics, 70(3):383-398.

Bond, L. A. and King, D. (1995). State high school graduation testing: Status and recommendations. Oak Brook, IL: North Central Regional Educational Laboratory.

Brueckner, J. K. (2003). Strategic interaction among governments: An overview of empirical studies. International Regional Science Review, 26(2):175-188.

Brueckner, J. K. and Saavedra, L. A. (2001). Do local governments engage in strategic propertytax competition? National Tax Journal, 54(2):203-229.

Calcagno, P. T. and Sobel, R. S. (2014). Regulatory costs on entrepreneurship and establishment employment size. Small Business Economics, 42(3):541-559.

Campbell, N. D., Heriot, K. C., and Jauregui, A. (2010). State regulatory spending: Boon or brake for new enterprise creation and income? Economic Development Quarterly, 24(3):243-250.

Chambers, D. and Collins, C. A. (2016). How do federal regulations affect consumer prices? an analysis of the regressive effects of regulation. Mercatus Working Paper, George Mason University, Arlington, VA.

Coffey, B., McLaughlin, P. A., and Tollison, R. D. (2012). Regulators and Redskins. Public Choice, 153(1-2):191-204.

Davies, A. (2014). Regulation and productivity. Mercatus Working Paper, George Mason University, Arlington, VA.

Dawson, J. W. and Seater, J. J. (2013). Federal regulation and aggregate economic growth. Journal of Economic Growth, 18(2):137-177. 
De Rugy, V. and Davies, A. (2009). Midnight regulations and the Cinderella effect. The Journal of Socio-Economics, 38(6):886-890.

Deskins, J. and Hill, B. (2010). Have state tax interdependencies changed over time? Public Finance Review, 38(2):244-270.

Devereux, M. P., Lockwood, B., and Redoano, M. (2007). Horizontal and vertical indirect tax competition: Theory and some evidence from the USA. Journal of Public Economics, 91(3):451-479.

Ed Counts Research Center (2017). State exit exam based on 10th grade standards or higher. http://http://www.edcounts.org/createtable/viewtable.php.

Elder, R. W., Lawrence, B., Ferguson, A., Naimi, T. S., Brewer, R. D., Chattopadhyay, S. K., Toomey, T. L., and Fielding, J. E. (2010). The effectiveness of tax policy interventions for reducing excessive alcohol consumption and related harms. American Journal of Preventive Medicine, 38(2):217-229.

Elhorst, J. P. (2009). Spatial panel data models. In Fischer, M. M. and Getis, A., editors, Handbook of Applied Spatial Analysis, chapter 2, pages 81-103. Springer, New York.

Elhorst, J. P. (2010). Applied spatial econometrics: Raising the bar. Spatial Economic Analysis, 5(1):9-28.

Elhorst, J. P. (2014). Spatial panel data models. In Spatial Econometrics: From Cross-Sectional Data to Spatial Panels, chapter 3, pages 37-93. Springer.

Elzinga, K. G., Tremblay, C. H., and Tremblay, V. J. (2015). Craft beer in the United States: History, numbers, and geography. Journal of Wine Economics, 10(3):242274.

Fell, J. C., Fisher, D. A., Voas, R. B., Blackman, K., and Tippetts, A. S. (2009). The impact of underage drinking laws on alcohol-related fatal crashes of young drivers. Alcoholism: Clinical and Experimental Research, 33(7):1208-1219. 
Fredriksson, P. G. and Mamun, K. A. (2008). Vertical externalities in cigarette taxation: Do tax revenues go up in smoke? Journal of Urban Economics, 64(1):3548.

Gardner, D. P. (1983). A nation at risk. Washington, DC: The National Commission on Excellence in Education.

Gelman, A. and Hill, J. (2006). Data analysis using regression and multilevel/hierarchical models. Cambridge University Press.

Gohmann, S. F. (2016). Why are there so few breweries in the south? Entrepreneurship Theory and Practice, 40(5):1071-1092.

Greene, J. P. (2001). High school graduation rates in the United States. Manhattan Institute for Policy Research.

Greene, J. P. and Winters, M. A. (2004). Pushed out or pulled up? Exit exams and dropout rates in public high schools. Manhattan Institute for Policy Research.

Hall, J. C. and Leeson, P. T. (2010). Racial fractionalization and school performance. American Journal of Economics and Sociology, 69(2):736-758.

Hanushek, E. A. (1986). The economics of schooling: Production and efficiency in public schools. Journal of Economic Literature, 24(3):1141-1177.

Hanushek, E. A., Kain, J. F., and Rivkin, S. G. (2009). New evidence about Brown v. Board of Education: The complex effects of school racial composition on achievement. Journal of Labor Economics, 27(3):349-383.

Heckman, J. J. and LaFontaine, P. A. (2010). The American high school graduation rate: Trends and levels. The Review of Economics and Statistics, 92(2):244-262.

Hemelt, S. W. and Marcotte, D. E. (2013). High school exit exams and dropout in an era of increased accountability. Journal of Policy Analysis and Management, $32(2): 323-349$. 
Hines, J. R. (2007). Taxing consumption and other sins. The Journal of Economic Perspectives, 21(1):49-68.

Hoffer, A. J. (2016). Special-interest spillovers and tobacco taxation. Contemporary Economic Policy, 34(1):146-157.

Hoffer, A. J. and Pellillo, A. (2012). The political economy of tobacco control spending. Applied Economics Letters, 19(18):1793-1797.

Hoffer, A. J., Shughart, W. F., and Thomas, M. D. (2014). Sin taxes and sindustry: Revenue, paternalism, and political interest. The Independent Review, 19(1):47-64.

Holcombe, R. G. (1997). Selective excise taxation from an interest-group perspective. In II, W. S., editor, Taxing Choice: The Predatory Politics of Fiscal Discrimination, pages 81-103. Transaction Publishers, New Brunswick(USA) and London(UK).

Howard, P., Bogart, T., Grabowski, A., Mino, R., Molen, N., and Schultze, S. (2017). U.s. wine market share, 2011. https://msu.edu/ howardp/winemarket.pdf.

Jackson, C. K., Johnson, R. C., and Persico, C. (2016). The effects of school spending on educational and economic outcomes: Evidence from school finance reforms. The Quarterly Journal of Economics, 131(1):157-218.

Jordan, S and Drenkard, S (2015). How high are wine taxes in your state? http: //taxfoundation.org/blog/how-high-are-wine-taxes-your-state.

Lacombe, D. J. and Flores, M. (2017). A hierarchical slx model application to violent crime in mexico. The Annals of Regional Science, 58(1):119-134.

LeSage, J. P. (2014). What regional scientists need to know about spatial econometrics. Available at SSRN: https://ssrn.com/abstract $=2420725$.

LeSage, J. P. and Dominguez, M. (2012). The importance of modeling spatial spillovers in public choice analysis. Public Choice, 150(3):525-545. 
LeSage, J. P. and Pace, R. K. (2009). Introduction to Spatial Econometrics. CRC Press, Boca Raton.

Luke, D. A. (2004). Multilevel modeling, volume 143. Sage Publications, Inc.

MacDonald, S. (1986). The impact of increased availability of wine in grocery stores on consumption: Four case histories. British Journal of Addiction, 81(3):381-387.

Malone, T. and Chambers, D. (2017). Quantifying federal regulatory burdens in the beer value chain. Agribusiness, 0(0):1-6.

Marchant, G. J. and Paulson, S. E. (2005). The relationship of high school graduation exams to graduation rates and SAT scores. Education Policy Analysis Archives, $13: 6$.

McLaughlin, P. A. and Williams, R. A. (2017). The consequences of regulatory accumulation and a proposed solution. http://dx.doi.org/10.2139/ssrn.2403602.

Miron, J. A. and Tetelbaum, E. (2009). Does the minimum legal drinking age save lives? Economic Inquiry, 47(2):317-336.

MKF Research, LLC (2007). The impact of wine, grapes and grape products on the american economy 2007: family businesses building value. https://www . wineinstitute.org/files/mfk_us_econ_report07.pdf.

Mulligan, C. B. and Shleifer, A. (2005). The extent of the market and the supply of regulation. The Quarterly Journal of Economics, 120(4):1445-1473.

Nelson, J. P. (1990). State monopolies and alcoholic beverage consumption. Journal of Regulatory Economics, 2(1):83-98.

Ou, D. (2010). To leave or not to leave? A regression discontinuity analysis of the impact of failing the high school exit exam. Economics of Education Review, $29(2): 171-186$. 
Palardy, G. J. (2013). High school socioeconomic segregation and student attainment. American Educational Research Journal, 50(4):714-754.

Papay, J. P., Murnane, R. J., and Willett, J. B. (2010). The consequences of high school exit examinations for low-performing urban students: Evidence from Massachusetts. Educational Evaluation and Policy Analysis, 32(1):5-23.

Raudenbush, S. W. and Bryk, A. S. (2002). Hierarchical linear models: Applications and data analysis methods, volume 1. Sage Publications.

Reardon, S. F. and Galindo, C. (2002). Do high-stakes tests affect students' decisions to drop out of school? evidence from NELS. In Annual Meeting of the American Educational Research Association, New Orleans, LA.

Sass, T. R. and Saurman, D. S. (1996). Efficiency effects of exclusive territories: Evidence from the Indiana beer market. Economic Inquiry, 34(3):597-615.

Spiegelhalter, D. J., Best, N. G., Carlin, B. P., and Van Der Linde, A. (2002). Bayesian measures of model complexity and fit. Journal of the Royal Statistical Society: Series B, 64(4):583-639.

Subramanian, S. (2010). Multilevel modeling. In Handbook of Applied Spatial Analysis, pages 507-525. Springer.

Sumner, W. G. (1892). The financier and the finances of the American revolution, volume 2. Dodd, Mead, and Company, New York.

The Wine Institute (2017). International trade policy. https://www.wineinstitute. org/international_trade_policy.

Thornton, J. (2013). American Wine Economics: An Exploration of the US Wine Industry. Univ of California Press.

Tiebout, C. M. (1956). A pure theory of local expenditures. The Journal of Political Economy, 64(5):416-424. 
US Department of Education (2017). Every Student Suceeds Act high school graduation rate non-regulatory guidance. https://www2.ed.gov/policy/elsec/leg/essa/ essagradrateguidance.pdf.

Warren, J. R. and Edwards, M. R. (2005). High school exit examinations and high school completion: Evidence from the early 1990s. Educational Evaluation and Policy Analysis, 27(1):53-74.

Warren, J. R., Jenkins, K. N., and Kulick, R. B. (2006). High school exit examinations and state-level completion and GED rates, 1975 through 2002. Educational Evaluation and Policy Analysis, 28(2):131-152.

Warren, R. W., Grodsky, E., and Lee, J. C. (2008). State high school exit examinations and postsecondary labor market outcomes. Sociology of Education, 81(1):77107.

Warren, R. W. and Jenkins, K. N. (2005). High school exit examinations and high school dropout in Texas and Florida, 1971-2000. Sociology of Education, 78(2):122143.

Wine and Vines (2017). Wine industry metrics. https://www. winesandvines.com/ template.. fm?section=widc\&widcDomain=wineries\&widcYYYYMM=201704.

Wine Institute (2016). Wine consumption in the US - The Wine Institute. http://www.wineinstitute.org/resources/statistics/article86. (Accessed on $11 / 17 / 2016)$ 